Provided for non-commercial research and education use. Not for reproduction, distribution or commercial use.

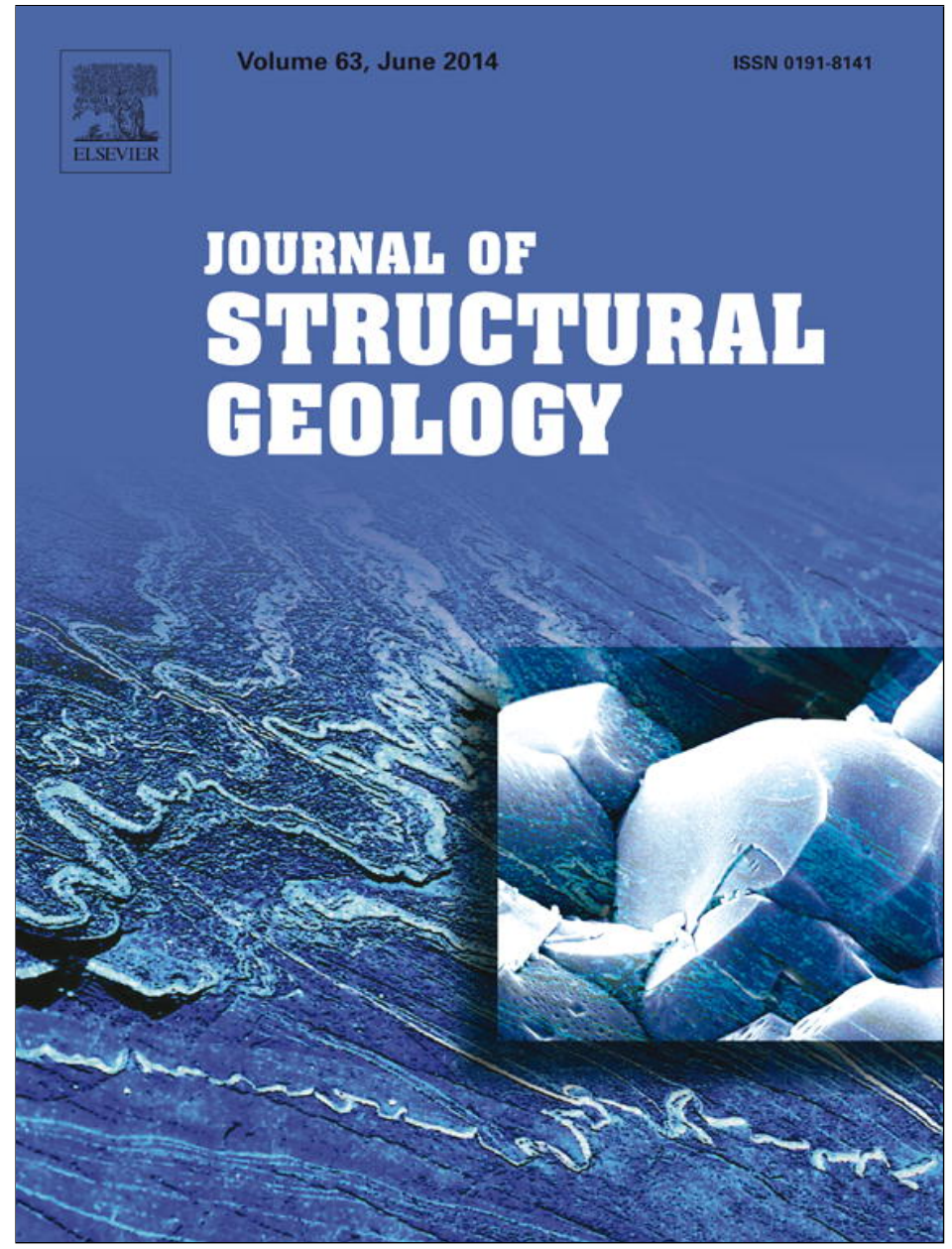

This article appeared in a journal published by Elsevier. The attached copy is furnished to the author for internal non-commercial research and education use, including for instruction at the authors institution and sharing with colleagues.

Other uses, including reproduction and distribution, or selling or licensing copies, or posting to personal, institutional or third party websites are prohibited.

In most cases authors are permitted to post their version of the article (e.g. in Word or Tex form) to their personal website or institutional repository. Authors requiring further information regarding Elsevier's archiving and manuscript policies are encouraged to visit:

http://www.elsevier.com/authorsrights 


\title{
The 3D quantitative lattice and shape preferred orientation of a mylonitised metagranite from Monte Rosa (Western Alps): Combining neutron diffraction texture analysis and synchrotron X-ray microtomography
}

\author{
M. Zucali ${ }^{\mathrm{a}, *}$, M. Voltolini ${ }^{\mathrm{b}}$, B. Ouladdiaf ${ }^{\mathrm{c}}$, L. Mancini $^{\mathrm{d}}$, D. Chateigner ${ }^{\mathrm{e}}$ \\ a DST - Dipartimento di Scienze della Terra “A. Desio”, Università degli Studi di Milano, Via Mangiagalli 34, 20133 Milano, Italy \\ ${ }^{\mathrm{b}}$ Earth Science Division, Lawrence Berkeley National Laboratory, \#1 Cyclotron Rd., 94720 Berkeley, CA, USA \\ ${ }^{\mathrm{c}}$ ILL, Institute Laue-Langevin, 38042 Grenoble Cedex 9 France, 6, Rue Jules Horowitz, B.P.156, France \\ ${ }^{\mathrm{d}}$ Elettra-Sincrotrone Trieste S.C.p.A., S.S, 14 - km 163,5 in Area Science Park, 34149 Basovizza, Trieste, Italy

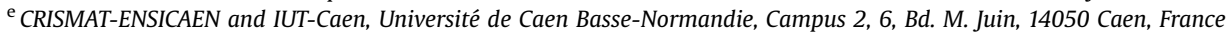

\section{A R T I C L E I N F O}

\section{Article history:}

Received 24 August 2013

Received in revised form

20 February 2014

Accepted 27 February 2014

Available online 16 March 2014

\section{Keywords:}

Neutron texture

Synchrotron microtomography

ODF

3D

\begin{abstract}
A B S T R A C T
Two complementary 3D techniques, neutron diffraction and synchrotron X-ray microtomography (SXR$\mu \mathrm{CT}$ ), were used to compare the Shape and Lattice Preferred Orientations of a mylonitised metagranite from the Monte Rosa unit (Western Alps, Italy). The goal of using these techniques was to obtain two different orientation distribution functions. Although the two functions describe relatively independent characteristics of the rock fabric, nonetheless they also exhibit close relationships to macroscopic fabrics and may be complementarily used to quantify rock fabrics and microstructures, thereby highlighting 3D features that cannot be obtained with either technique, if used independently. We describe an approach that can be potentially useful in various disciplines, e.g., structural geology, rock mechanics, tectonics and geophysics, when a complete data set of preferred orientations and size distribution is needed.

Micas display a strong orthorhombic symmetry between mesoscopic lineation and microscopic SPO and LPO, whereas quartz and feldspars are characterised by a monoclinic symmetry between mesoscopic lineation and LPO. These observations suggest a rheological decoupling between the weak phase mica layers and the stronger quartz + feldspar layers. This mechanical decoupling occurred during the Alpine subduction-collision, when the Monte Rosa unit was part of the Insubric Line system and accommodated large vertical strain.
\end{abstract}

(c) 2014 Elsevier Ltd. All rights reserved.

\section{Introduction}

Following recent developments at synchrotron light sources and neutron facilities, different techniques used for measuring microstructures (e.g., Cloetens et al., 1997) have become increasingly available to geoscientists interested in the quantification of rock fabrics (Tafforeau et al., 2006; Jerram and Higgins, 2007; Voltolini et al., 2011b; Baker et al., 2012; Barreiro and Catalán, 2012). In parallel, new software packages have been developed to permit faster and more accurate data analysis of both diffraction and microtomography datasets (e.g., Blob3D: Ketcham, 2005a; Maud:

\footnotetext{
* Corresponding author.

E-mail address: Michele.Zucali@unimi.it (M. Zucali).
}

Lutterotti et al., 1999; Beartex: Wenk et al., 1998; MTEX: Hielscher and Schaeben, 2008; Mainprice et al., 2011; Pore3D: Brun et al., 2010).

The anisotropy of a rock (i.e., its fabric) is the result of the Lattice and Shape Preferred Orientation (LPO and SPO, respectively) of the rock's constituents and is usually highlighted by foliations and/or lineations (Turner and Weiss, 1963; Nicolas, 1987; Karato, 2008; Sullivan, 2013). The preferred orientation in terms of both lattice and shape of minerals (and pores) controls the anisotropy of their physical properties (e.g., Voltolini et al., 2008) such as the magnitude of seismic wave velocities as a function of direction in a clay + silt material at different degrees of compaction. Accordingly, a comprehensive quantification of the LPO and SPO in rocks and in materials, more generally becomes of great importance for improving our understand and models concerning the anisotropy 
of mechanical properties in polyphase materials. Indeed, in crystalline rocks, the LPO and SPO also record the deformation effects. Therefore, their characterisation can be used to reconstruct the deformation history for the host in terms of i) the strain state (e.g., Choukroune and Gapais, 1983); ii) active deformation mechanisms (Nicolas and Poirier, 1976; Ismaîl and Mainprice, 1998; Passchier and Trouw, 2005); and iii) the shear sense criteria (Cobbold et al., 1987; Gapais and Cobbold, 1987).

However, quantitative preferred orientation data are commonly taken in 2D due to the availability of analytical techniques (see Baker et al., 2012 for a more comprehensive discussion), where studies that compare 3D LPO and SPO data from the same sample have never been attempted so far. This contribution aims to produce an effective procedure for the 3D quantification of the LPO and SPO of a rock sample with a complex deformation history.

The proposed combination of neutron diffraction and synchrotron X-ray microtomography (SXR- $\mu \mathrm{CT})$ is extremely appealing for the quantification of anisotropy because the two techniques are based on completely different paradigms and can be used on samples of comparable size, or even on the same sample. Neutron (and X-ray) diffraction can provide structural information and the quantification of LPO (Baker and Wenk, 1972; Chateigner et al., 2000; Wenk et al., 2001, 2010; Zucali et al., 2010, 2012, 2014). By using the Rietveld method (Rietveld, 1969), it is generally possible to obtain the crystallographic properties of the different phases (such as lattice parameters, crystallite size, crystal structure, microstrain, etc.), the weight fractions, and ODFs for the different minerals. However, diffraction cannot provide information about the shape of the mineral grains, and in fact, the value of crystallite size that can be measured via diffraction is the average size of the coherently scattering domains, even though the mineral grains can be made of one or more crystallites (Young, 1993).

In this scenario, the combination of neutron diffraction and SXR$\mu \mathrm{CT}$ becomes ideal because both approaches can handle samples of approximately $1 \mathrm{~cm}^{3}$, making the powder diffraction approach less susceptible to issues of grainy resolution, thus adhering to the requirements of powder diffraction. In such a case, relatively large crystals can be tolerated in the sample whereas X-ray diffraction with a smaller beam size and the weaker penetration restrict the sample thickness and crystallite size of the sample constituents. Ideally, SXR$\mu \mathrm{CT}$ provides a range of information that neutron diffraction cannot obtain, where the most important is the spatial arrangement of the different phases in the specific sample, when the absorption contrast is sufficiently strong to allow for phase segmentation in addition to the morphology of the different mineral grains. Morphometric analysis can provide the grain-size distribution, aspect ratio, surface area and a series of more specific morphometric parameters (e.g., Zandomeneghi et al., 2010), as well as ODFs similar to that obtained with neutron diffraction, although based on SPO instead of the LPO. Even non-scattering objects can be analysed to quantify anisotropy, as for example, a SPO analysis of vesicles in volcanic rocks has shown (Voltolini et al., 2011b). This example highlights another clear advantage of the approach when compared with EBSD, where the ODF for the pores in a rock cannot be obtained.

This contribution will produce a simple yet effective example of the combination of these two techniques and their application to a crystalline rock sample that is characterised by extreme lineated fabric (L-mylonite). The development of fabric anisotropies will also be discussed in terms of strain patterns during deformation and the crystallographic ODF will be used to calculate magnitudes and directional variability of seismic velocities to estimate the influence of the LPO anisotropies. This work aims primarily to define a procedure for comparing quantitative results from neutron diffraction and SXR- $\mu \mathrm{CT}$ and emphasises the strength of the two approaches when combined.

\section{Materials and methods}

We investigate an orthogneiss from the Monte Rosa Unit (Western Penninic Alps, Italy; UTM coordinates: 445'871 m E 5'103'130 m N, WGS84 - World Geodetic System of 1984 datum, $32 \mathrm{~N}$ ). This orthogneiss is characterised by a highly strained lineated fabric (e.g., L-mylonite) that developed during the Alpine tectonometamorphic evolution (Fig. 1 and Supplementary material). We first proceed by extracting the LPO and SPO data, as obtained by neutron diffraction and phase-contrast SXR- $\mu \mathrm{CT}$, respectively. Then, ODFs are calculated from both the LPO and SPO datasets.

\subsection{Sample description: mesostructures, microstructures and chemistry}

Specimens of a highly lineated mylonitic orthogneiss (L-fabric) from the Monte Rosa Unit (Upper Penninic domain, Italian Alps, Fig. 1) were collected for SPO and LPO orientation analysis. This specific type of rock has been used since the Roman age as a building stone with the name "Beola" (Cavallo et al., 2004a, 2004b). Its well-developed planar or linear mesoscopic fabrics makes it highly suitable for the cutting of flat pieces to be used as building stones.

The mylonitic lineation is Alpine in age (25-27 Ma, Engi et al., 2001 ) and is macroscopically marked by the preferred orientation of quartz ribbons, $\mathrm{K}$-feldspar elongated grains and mica aggregates (Fig. 2). Pressure conditions for the development of the mylonitic lineation were estimated to be $8 \pm 3 \mathrm{kbar}$, whereas the temperature was estimated to be $450-500{ }^{\circ} \mathrm{C}$ by Borghi et al. (1996) and Le Bayon et al. (2006a; 2006b) and $550-600{ }^{\circ} \mathrm{C}$ by Gasco and Borghi (2011).

The mineral lineation trends NE and plunges $0-10^{\circ}$ (Fig. 2), almost parallel to the Canavese Line and the boundary with the Sesia-Lanzo Zone. The lineation poles cluster about a mean orientation of 060/00. Statistical analysis (Fisher and Embleton, 1987) describes a shape parameter $K=4.12$ and a strength parameter $C=5.81$ that is consistent with plotting in the constructional field of a Flinn plot (Fig. 2c). Likewise, the magnitudes of the eigenvalues are consistent with a strongly prolate distribution as should be expected for a well-developed lineation (Fig. 2c) (Woodcock and Naylor, 1983).

The main constituent minerals are quartz (30-40\%), albite (15$20 \%)$, K-feldspar (5-15\%), biotite (10-15\%) and phengitic mica (10$15 \%)$. At the microscopic scale, ribbon quartz characterises the lineated fabric (Fig. 3), which is marked by 1 - to 2 -mm-thick mineral layers of alternating quartz + mica and feldspar + mica. Quartz forms aggregate into 0.2 to 0.7 -mm-sized grains, displaying large domains of homogenous extinction (i.e., sub-grains), although undulose extinction also occurs and is locally associated with deformation bands. The grain aggregates are equigranular to inequigranular, and the boundaries are interlobate. Conversely, feldspar-rich layers show smaller grain sizes, always less than $0.2 \mathrm{~mm}$, with grain aggregate shapes that are equigranular and grain boundaries of interlobate geometry. The SPO is well marked in micas but is less intense in quartz and is poorly developed in plagioclase and feldspar.

The compositions of rock-forming minerals were analysed by SEM-EDS at Dipartimento di Scienze della Terra "A. Desio," Università degli Studi di Milano, Italy, for an accelerating voltage of $20 \mathrm{kV}$ and a current of $190 \mathrm{pA}$ (Table 1). Matrix corrections and data reduction used the $Z A F$ procedure, which corrects for atomic number $(\mathrm{Z})$, absorption $(\mathrm{A})$ and fluorescence $(\mathrm{F})$. Mica displays a phengite composition with a $\mathrm{Si}^{4+}$ content higher than 3.10 a.p.f.u. Biotite displays a relatively high $\mathrm{Ti}$ content, most likely inherited from the original igneous biotites, while Xmg varies from 30 to $40 \%$. 


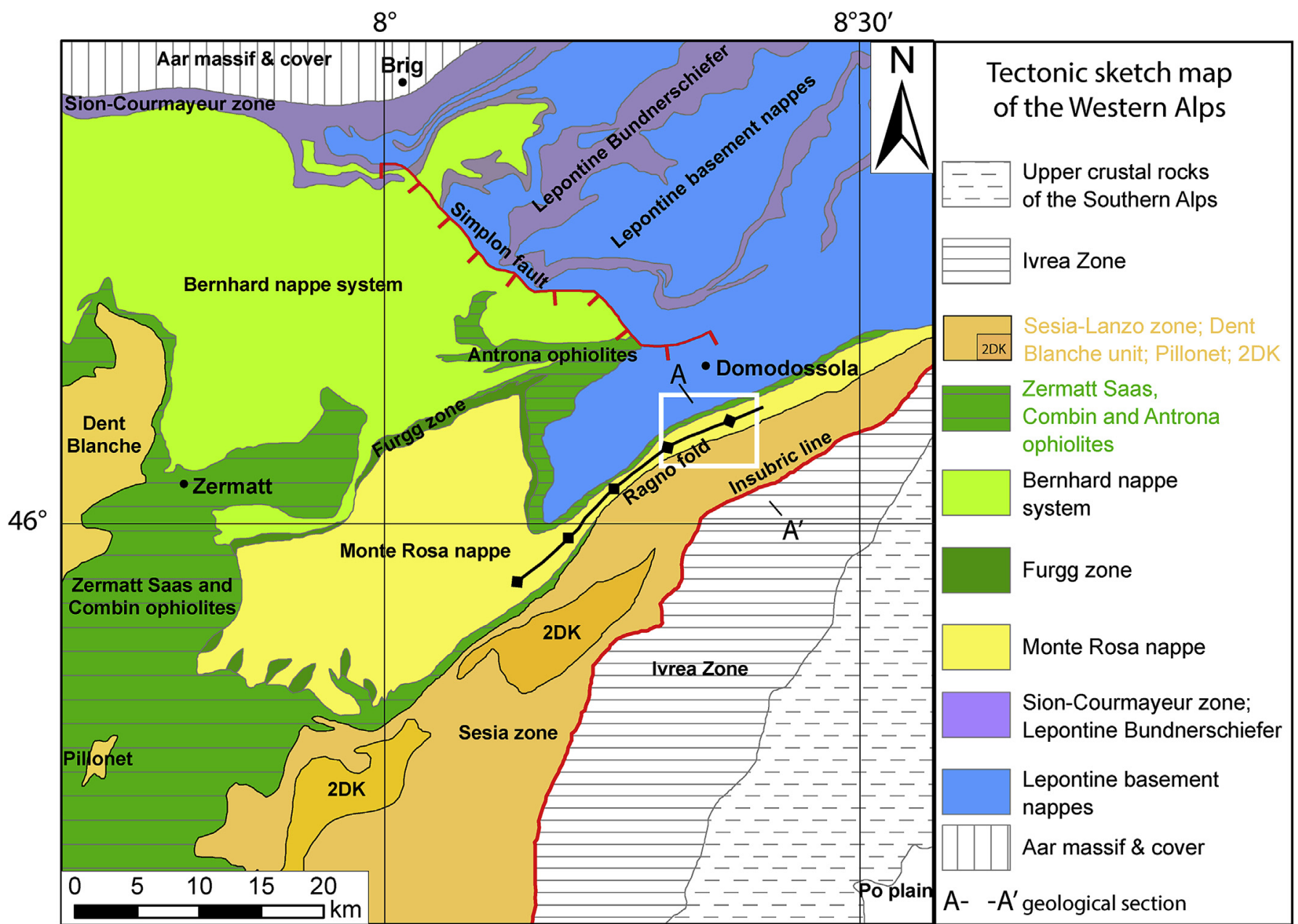

A

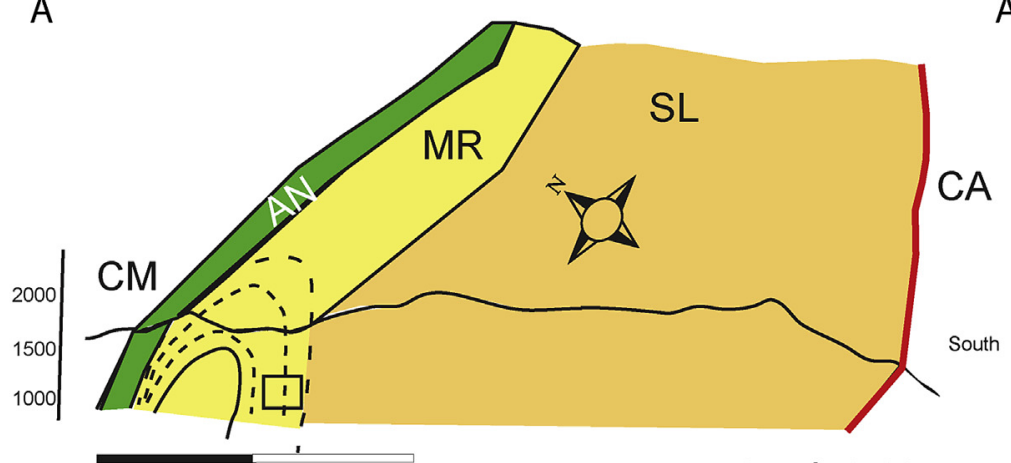

$A^{\prime}$

CM: Camughera-Moncucco;

AN: Antrona Ophiolite;

MR: Monte Rosa;

SL: Sesia-Lanzo;

CA: Canavese

(redrawn after Reinhardt, 1966)

$\therefore$ Fold traces

\section{Samples position}

Fig. 1. Tectonic sketch map for the Western Alps across the Po plain (IT) and Brig (CH). White box is location of the studied sample. Position of the section line AA' is shown. Representative profile along AA' redrawn after Reinhardt (1966).

K-feldspar contains a small amount of $\mathrm{Ab}(\mathrm{Xab}<10-13 \%)$, whereas plagioclase has contents of $\mathrm{Ab}(\mathrm{Xab})>80 \%$ and $\mathrm{An}$ (Xan) ranging from 15 to $18 \%$.

According to Cavallo et al. (2004a), all samples display compositions typical of peraluminous granites (Variscan granitoid according to Bigi et al., 1990) with $\mathrm{SiO}_{2}$ contents varying from 70 to 73 wt.\%. Several mechanical properties have also been measured, especially those related to the quality assessment of commercial stones, including wear resistance, flexural strength, water absorption, compressional breaking load, impact testing, thermal linear expansion and Knoop micro hardness (see Cavallo et al., 2004a, 2004b and references therein for details). Most of these properties are influenced by the strong fabric anisotropies described above.

\subsection{SPO and LPO data measurements}

The sample reference system for all figures, pole figures and all stereonets was chosen with respect to the mesoscopic fabric elements (Fig. 4), i.e., the $X$-direction is parallel to the lineation direction, and the $Y$-direction is perpendicular to the lineation within 


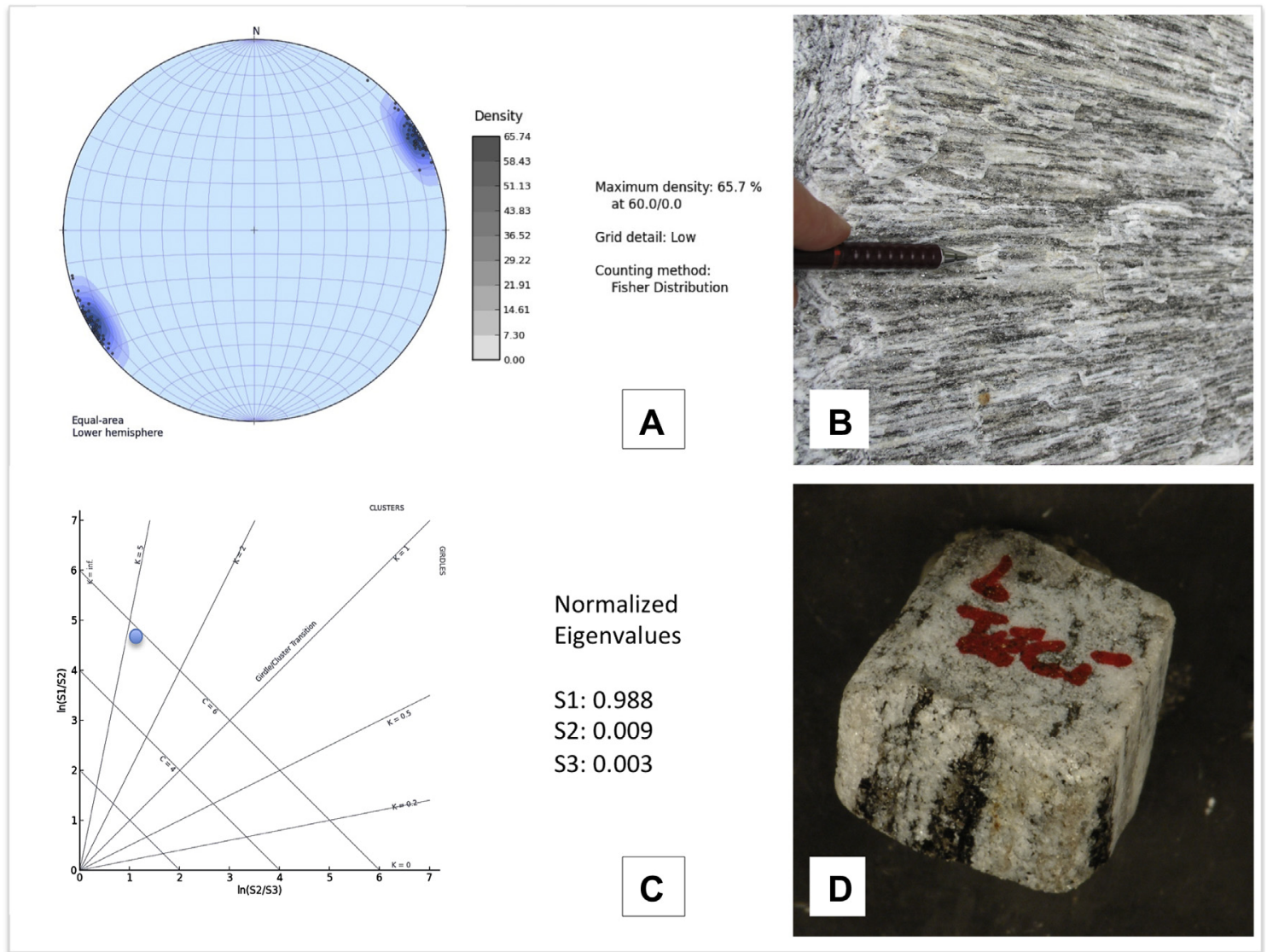

Fig. 2. A) Equal-area lower hemisphere projection of mesoscopic lineations (101 data) and data density, Kamb contours for sample LM1; B) Macroscopic mineral lineation marked by SPO of biotite, phengite and feldspar; C) Flinn-type diagram showing the relations between the three eigenvalues for the orientation tensor of mineral lineation; D) Volume $\approx 1 \mathrm{~cm}^{3}$ used for quantitative texture analysis by neutron diffraction.
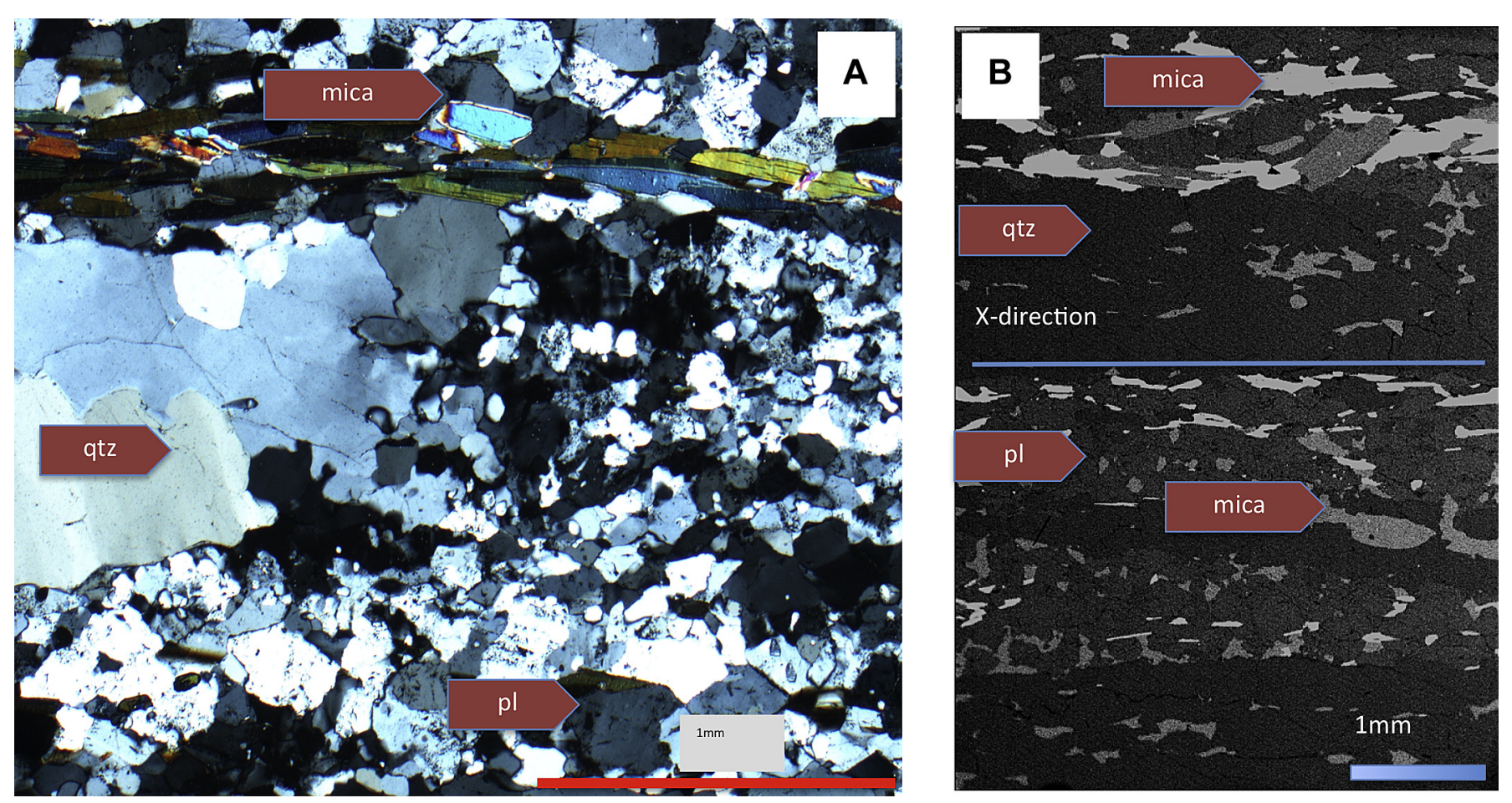

Fig. 3. Microstructural features of LM1: A) Microscopic image with cross-polarized light showing the mineral lineation marked by mica-rich layers, quartz rods and plagioclase aggregates; B) Back-Scattering electron image from the Scanning Electron Microscope (SEM) showing the mineral lineation. Two micas are white or light grey, quartz are dark grey, and feldspar is intermediate grey. 
Table 1

Selected compositional analysis of rock-forming minerals for LM1 sample.

\begin{tabular}{|c|c|c|c|c|c|c|}
\hline \multicolumn{7}{|c|}{ Selected mineral analyses of LM1 sample } \\
\hline \multirow{2}{*}{$\frac{\text { Sample }}{\text { an. }}$} & \multirow{2}{*}{$\frac{\text { LM9 }}{\text { Mica }}$} & \multirow{2}{*}{$\begin{array}{l}\text { Sample } \\
\text { an. }\end{array}$} & \multirow{2}{*}{$\frac{\text { LM40 }}{\text { Biotite }}$} & \multirow{2}{*}{$\frac{\text { Sample }}{\text { an. }}$} & \multirow{2}{*}{$\frac{\mathrm{LM} 10}{\mathrm{k} \text {-feldspar }}$} & \multirow{2}{*}{$\frac{\text { LM30 }}{\text { Albite }}$} \\
\hline & & & & & & \\
\hline $\mathrm{K}_{2} \mathrm{O}$ & 11.30 & $\mathrm{~K}_{2} \mathrm{O}$ & 9.65 & $\mathrm{~K}_{2} \mathrm{O}$ & 15.62 & 0.29 \\
\hline $\mathrm{CaO}$ & 0.08 & $\mathrm{CaO}$ & 0.00 & $\mathrm{CaO}$ & 0.00 & 4.05 \\
\hline $\mathrm{TiO}_{2}$ & 1.66 & $\mathrm{TiO}_{2}$ & 2.98 & $\mathrm{TiO}_{2}$ & 0.04 & 0.00 \\
\hline $\mathrm{Cr}_{2} \mathrm{O}_{32}$ & 0.00 & $\mathrm{Cr}_{2} \mathrm{O}_{3}$ & 0.00 & $\mathrm{Cr}_{2} \mathrm{O}_{3}$ & 0.00 & 0.00 \\
\hline $\mathrm{MnO}$ & 0.11 & $\mathrm{MnO}$ & 0.59 & $\mathrm{MnO}$ & 0.00 & 0.00 \\
\hline FeOt & 3.71 & FeOt & 23.14 & $\mathrm{FeO}$ & 0.00 & 0.05 \\
\hline $\mathrm{NiO}$ & 0.00 & $\mathrm{NiO}$ & 0.00 & $\mathrm{NiO}$ & 0.00 & 0.00 \\
\hline $\mathrm{Na}_{2} \mathrm{O}$ & 0.56 & $\mathrm{Na}_{2} \mathrm{O}$ & 0.76 & $\mathrm{Na}_{2} \mathrm{O}$ & 1.31 & 10.24 \\
\hline $\mathrm{SiO}_{2}$ & 46.32 & $\mathrm{SiO}_{2}$ & 34.88 & $\mathrm{SiO}_{2}$ & 63.80 & 61.13 \\
\hline $\mathrm{Al}_{2} \mathrm{O}_{3}$ & 30.30 & $\mathrm{Al}_{2} \mathrm{O}_{3}$ & 17.11 & $\mathrm{Al}_{2} \mathrm{O}_{3}$ & 18.70 & 22.32 \\
\hline \multirow[t]{3}{*}{$\mathrm{MgO}$} & 1.60 & $\mathrm{MgO}$ & 6.03 & $\mathrm{MgO}$ & 0.01 & 0.10 \\
\hline & & FeO. calc & 20.84 & & & \\
\hline & & $\mathrm{Fe}_{2} \mathrm{O}_{3}$. calc & 2.53 & & & \\
\hline Total & 95.62 & Total & 95.35 & Total & 99.47 & 98.18 \\
\hline \multicolumn{2}{|c|}{ Cations per $11 \mathrm{Ox}$. } & \multicolumn{2}{|c|}{ Cations per $11 \mathrm{Ox}$. } & \multicolumn{2}{|c|}{ Cations per $80 x$} & \\
\hline $\mathrm{Si}(\mathrm{T})$ & 3.14 & $\mathrm{Si}$ & 2.72 & $\mathrm{Si}$ & 2.97 & 2.77 \\
\hline Al total & 2.42 & Al. IV & 1.28 & $\mathrm{Al}$ & 1.03 & 1.19 \\
\hline Al.IV (T) & 0.86 & Al. VI & 0.29 & $\mathrm{Ti}$ & 0.00 & 0.00 \\
\hline Al.VI (M2) & 1.57 & $\mathrm{Ti}$ & 0.17 & $\mathrm{Cr}$ & 0.00 & 0.00 \\
\hline $\mathrm{Ti}(\mathrm{M} 2)$ & 0.08 & $\mathrm{Cr}$ & 0.00 & $\mathrm{Fe}^{++}$ & 0.00 & 0.00 \\
\hline $\mathrm{Cr}(\mathrm{M} 2)$ & 0.00 & $\mathrm{Fe}^{3+}$ & 0.15 & $\mathrm{Mn}$ & 0.00 & 0.00 \\
\hline Mn (M2) & 0.01 & $\mathrm{Fe}^{2+}$ & 1.36 & $\mathrm{Mg}$ & 0.00 & 0.01 \\
\hline Ni (M2) & 0.00 & $\mathrm{Mn}$ & 0.04 & $\mathrm{Ni}$ & 0.00 & 0.00 \\
\hline $\mathrm{Fe}^{2+}$ tot & 0.21 & $\mathrm{Mg}$ & 0.70 & $\mathrm{Ca}$ & 0.00 & 0.20 \\
\hline $\mathrm{Fe}^{2+}(\mathrm{M} 2)$ & 0.21 & $\mathrm{Ni}$ & 0.00 & $\mathrm{Na}$ & 0.12 & 0.90 \\
\hline Mg. tot & 0.16 & $\mathrm{Ca}$ & 0.00 & K & 0.93 & 0.02 \\
\hline $\mathrm{Mg}(\mathrm{M} 2)$ & 0.16 & $\mathrm{Na}$ & 0.11 & & & \\
\hline $\mathrm{Fe}^{2+}(\mathrm{M} 1)$ & 0.00 & $\mathrm{~K}$ & 0.96 & & & \\
\hline Mg (M1) & 0.00 & & & & & \\
\hline Ca (M1) & 0.01 & & & Xan & 0.00 & 17.94 \\
\hline $\mathrm{Na}(\mathrm{A})$ & 0.07 & & & Xsan & 88.73 & 1.48 \\
\hline $\mathrm{K}(\mathrm{A})$ & 0.98 & Xmg & 34.01 & Xab & 11.27 & 80.84 \\
\hline
\end{tabular}

the foliation plane, while the $Z$-direction is normal to both the lineation and foliation.

The quantification of preferred orientation, especially the LPO, in materials is usually done via Electron Back-Scattering Diffraction (EBSD) techniques. While this technique is commonly applied for this type of analysis, it has limitations that a combination of different techniques, such as the LPO from neutron diffraction and SPO from Synchrotron X-Ray-Computed microtomography (SXR$\mu \mathrm{CT}$ ), can overcome. One limitation of EBSD is that it is not a true 3D technique because EBSD is essentially a surface-sampling approach, so $3 \mathrm{D}$ volume analysis with spatially referenced data in that volume is not available, unlike with a combination of neutron diffraction and SXR- $\mu$ CT. Moreover, EBSD is a destructive technique because the sample must be cut and perfectly polished. Neutron diffraction and SXR- $\mu$ CT potentially can be used on a same sample, often without the need to prepare the sample, provided that the size of the sample is compatible with the experimental setup. This approach permits the full preservation of important samples, such as meteorites (Friedrich et al., 2008) and archaeological artefacts (Artioli, 2007). EBSD also requires samples with a well-defined crystallinity and crystallite size. Thus, when dealing with weathered samples or samples containing clays, X-ray and neutron diffraction techniques are better suited than EBSD (e.g., see Wenk et al., 2010).

SPO analysis based on surfaces from approach such as optical microscopy, SEM or EBSD grain maps may be unreliable in strongly anisotropic samples, unless samples are gathered from a minimum of three perpendicular orientations (see Sahagian and Proussevitch, 1998; Shea et al., 2010). In contrast, the analysis of 3D digitally derived datasets that do not necessitate predetermined spatially varied sampling geometries and has clear advantages, because the sample volume can be examined as a whole or considered from a variety of perspectives utilizing morphometric parameters to quantify the microstructure (e.g., Fig. 5).

\subsection{Synchrotron X-ray microtomography measurements}

The SXR- $\mu$ CT measurements were performed on the SYRMEP (SYnchrotron Radiation for MEdical Physics) beamline (Tromba et al., 2010) (Fig. 3) at the third generation synchrotron of the Elettra Synchrotron Light Laboratory of Trieste (http://www.elettra. trieste.it). At the SYRMEP beamline, the X-rays are provided by a bending magnet source, and the sample is placed at a distance of approximately $23 \mathrm{~m}$ from the source. At the sample stage, a monochromatic, laminar X-ray beam with a maximum area of
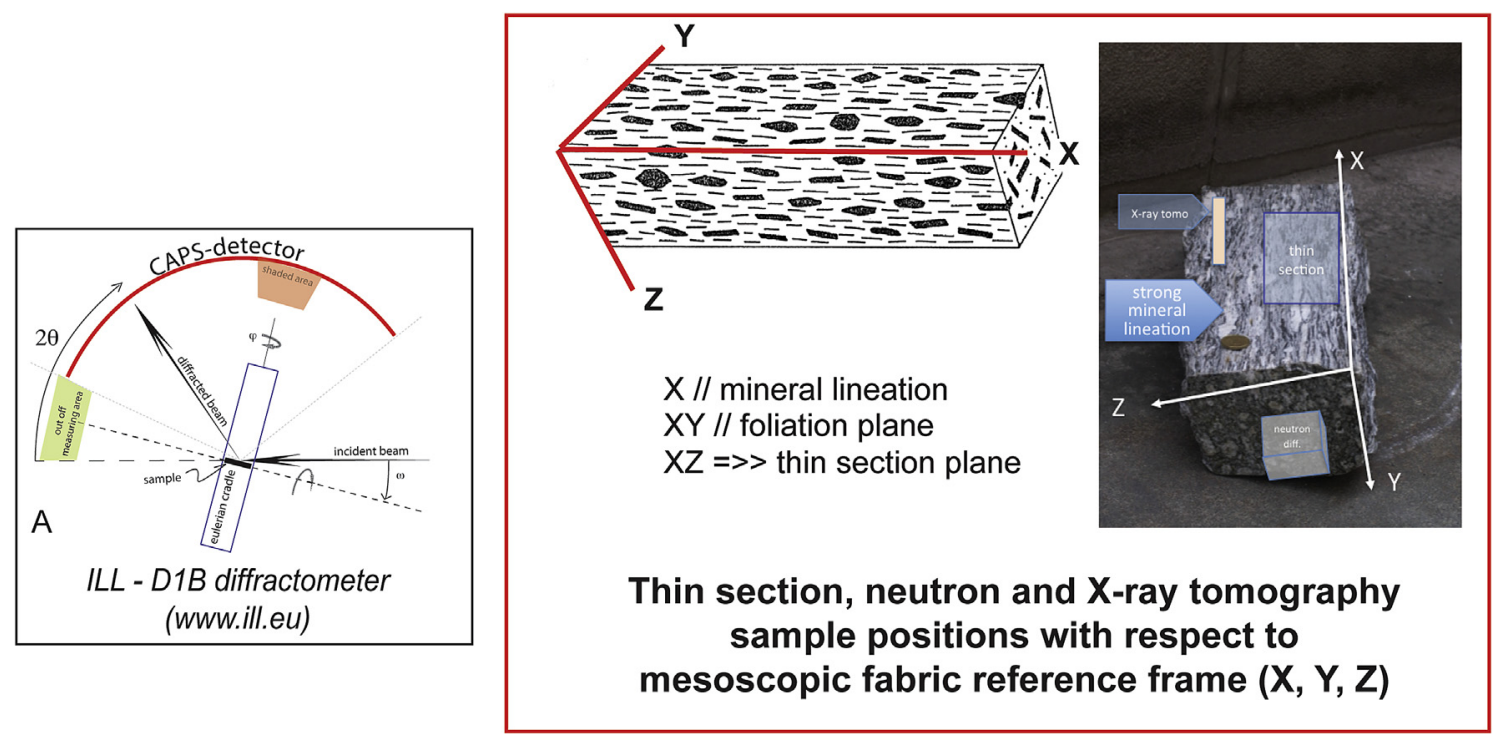

Fig. 4. Instrumental setup for the D1B diffractometer at ILL Institute (Grenoble) and illustrated mesoscopic fabric reference frame. Thin section, neutron and X ray sample positions are shown. 

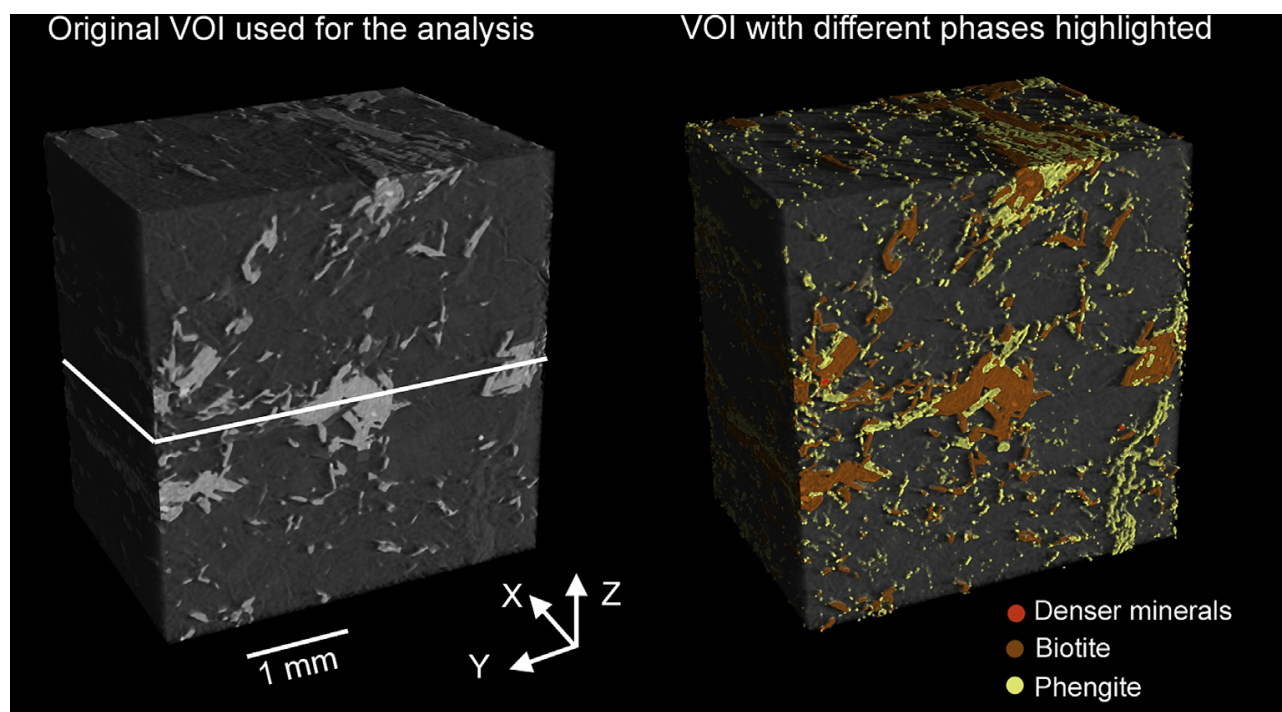

VOI better showing the distributon of Biotite

\section{Section highlighted in the volume above}

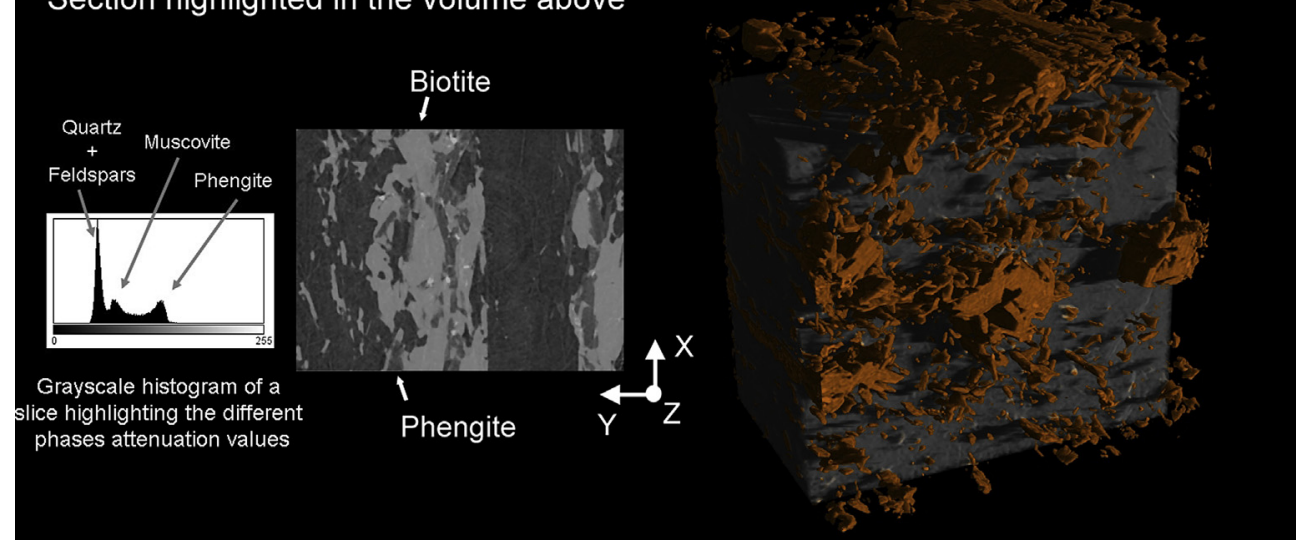

Fig. 5. Selected VOI obtained from the synchrotron X-ray microtomography experiments. In the upper left volume rendering and related slice below the grey levels of the different phases, the related histogram shows attenuation values for the different mineral phases. On top-right the VOI, biotite (brown), phengite (yellow), and denser minerals (red) are shown. The coordinate system is as in Fig. 4. (For interpretation of the references to colour in this figure legend, the reader is referred to the web version of this article.)

approximately $160 \times 6 \mathrm{~mm}$ is provided. The monochromator is based on a double Si(111) crystal system working in Bragg configuration, and the system can be tuned to provide an X-ray monochromatic beam within the energy range of $8.3-38 \mathrm{keV}$, with an energy resolving power of approximately $10^{-3}$.

The good spatial coherence of the X-ray beam permits use of the phase contrast effect to enhance the small features in a sample (Cloetens et al., 1996). In our measurements, we used free-space propagation to work in the "near field" Fresnel diffraction zone ( $d<<a^{2} / \lambda$, with $d=$ sample-to-detector distance, $a=$ size of the feature of interest measured perpendicularly to the beam direction, $\lambda=$ wavelength), thereby enhancing the edges of the objects. This setup has proven to be very important for obtaining better thinobject contrast, such as the micas in our sample set. At this sample-detector distance, with the resolution used (relatively low to provide a larger field of view), the phase contrast effect in size result is comparable with the image px size, so that the phase contrast artefacts do not significantly alter the shape of the object. Furthermore, the borders are more prominent than with more absorption-oriented tomography setups.

The measurements were taken from rock samples with a size of approximately $3 \times 4 \times 20 \mathrm{~mm}$ onto a high-resolution rotating stage. The energy chosen for the measurement was $28 \mathrm{keV}$, which was found to provide the best contrast/transmission compromise for this sample, and the sample-to-detector distance $d$ was set to $500 \mathrm{~mm}$. We acquired 1800 projections over a $180^{\circ}$ sample rotation, and the exposure time per projection was $1 \mathrm{~s}$. The projections were recorded with a 12-bit water-cooled CCD camera $(4008 \times 2672$ pixels, $4.5 \times 4.5 \mu \mathrm{m}$ effective pixel size $)$. In this case, we worked with a binning $2 \times 2$ of the pixel obtaining an active input area of $18(\mathrm{~h}) \times 12(\mathrm{v}) \mathrm{mm}$ on the sensor with a final voxeledge size of $9 \mu \mathrm{m}$. Slice reconstruction was performed using the GRIDREC algorithm (Dowd et al., 1999), implemented in the SYRMEP_Tomo_Project 4.0 software custom-developed at the beamline, which was run on the Elettra server to provide fast reconstructions. The reconstructed slices were visualised with ImageJ software, while the volume renderings were obtained by the VGStudio MAX 2.0 commercial software.

\subsection{Neutron diffraction texture analysis}

The measurement of single pole figures does not allow a fully quantitative texture analysis, even if measured completely, so for comparisons between samples (e.g., porosity, stress/strain states, 
particle sizes and phase ratios), pole figure normalisation must be performed (Bunge and Esling, 1982). The normalisation can only be operated via a refinement of the orientation distribution function (ODF), which backwards informs the calculation of the texture strength and all texture components. Here, we follow the procedure described and applied by Zucali et al. (2002) for the Quantitative Texture Analysis of rocks.

The high penetration and high flux of neutrons available at the nuclear reactor at the Institute Laue-Langevin (Grenoble, France) allows for the measurement of samples with volumes of approximately $1 \mathrm{~cm}^{3}$ within a few hours (Tartarotti et al., 2011; Zucali et al., 2012). For a typical scan, approximately 1400 measurements are needed for each complete pole figure, where the integral over a pole figure is 1 m.r.d. (multiple of the random distribution). Here, we present the results from the D1B diffractometer at the Institute Laue-Langevin (Fig. 4 and http://www.ill.eu). For this technique, monochromatic radiation is used with a pyrolitic graphite (002) monochromator wavelength of $\lambda=2.52 \AA$, flux $=6^{*} 10^{6} \mathrm{n}^{*} \mathrm{~cm}^{-2} \mathrm{~s}^{-1}$ and max beam-size $=2 * 5 \mathrm{~cm}^{2}$. The intensities are measured by rotating the sample around two axes with a goniometer $(\varphi=0-355$ by $5^{\circ}$ and $\chi=0-90$ by $5^{\circ}$, see Fig. 4a). A Curved Position-Sensitive Detector (CAPS in Fig. 4a) with an angular range $2 \theta=80^{\circ}$ and a resolution of $0.2^{\circ}$ is used to acquire simultaneously the diffracting

A Particle size distribution for Biotite and Phengite

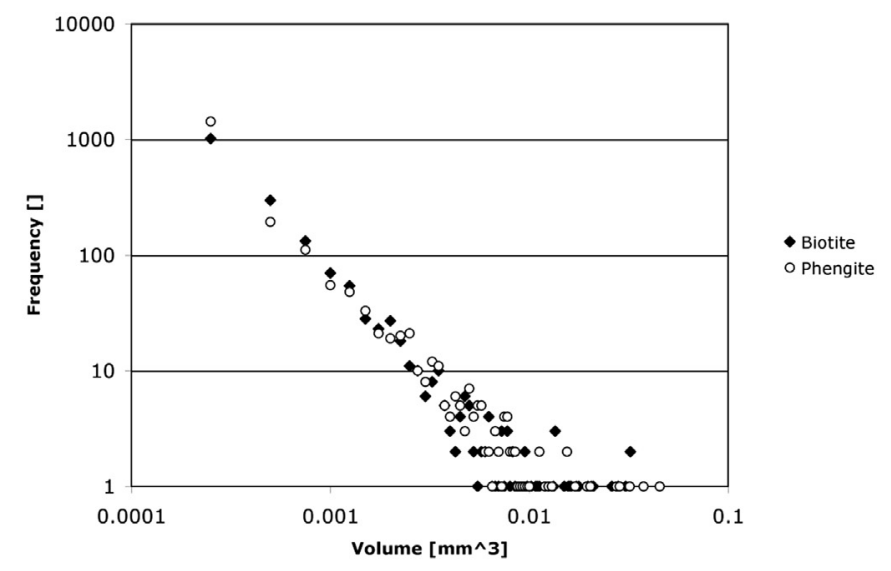

B Frequency distribution \% of particles Aspect Ratios

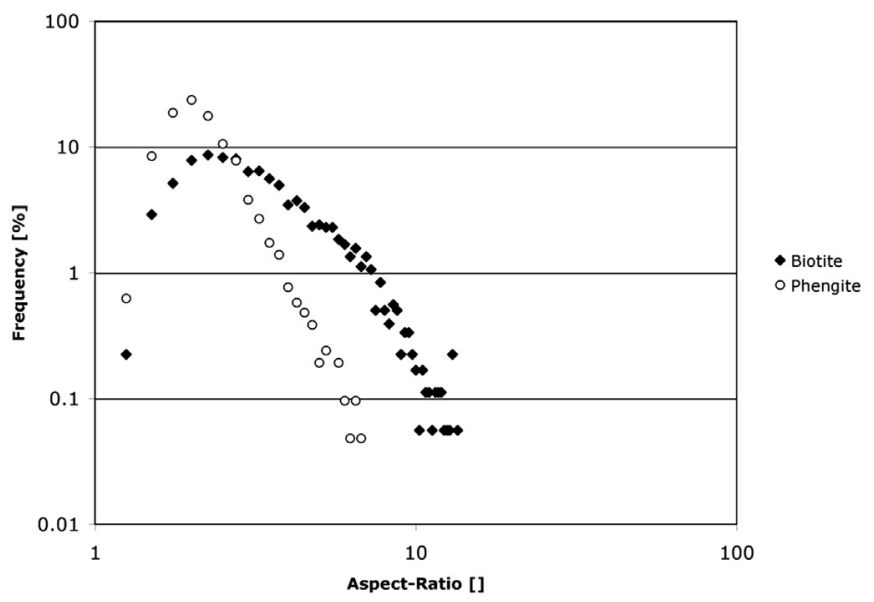

Fig. 6. A) Particles size distributions, obtained from the analysis of the synchrotron $X$ ray microtomography datasets for biotite and phengite. B) Distribution of the aspectratios for biotite and phengite grains. lattice planes at different Bragg angles. This result is $72 * 19=1368$ measured scans over the accessible $2 \theta$ range.

Numerical integration is not suited for obtaining satisfactory reliability of the ODF determination because of the relatively low $2 \theta$ resolution, so either a Rietveld texture analysis or a peak fit separation should be chosen (Howard and Preston, 1989) to resolve the overlaps. The latter is less likely to separate the exact and/or strong overlaps with respect to the Rietveld method (Young, 1993). In the analysis presented here, Rietveld texture analysis (Matthies et al., 1997) was performed using the software package MAUD (Materials Analysis Using Diffraction: Lutterotti et al., 1999), by considering quartz, phengitic-mica, biotite, feldspar and albite to be the only phases present in the sample. MAUD uses a Rietveld core routine to compute spectra and the Le Bail algorithm (see again Matthies et al., 1997) to extract the differences between the random and textured intensities for each computed peak. These spectra are the basis for computing the ODF using EWIMV (Liu et al., 1993). Finally, the spectra are recomputed using the results from the ODF for the next Rietveld iteration step. From the ODF obtained by the Rietveld analysis, the Pole Figures (PFs) can be calculated. PFs represent the orientation of one lattice plane $(\mathrm{hkl})$ with respect to the sample coordinate system. The same representation is commonly used for lattice plane orientations as obtained from $U$ stage, X-ray or EBSD. In this contribution, the PFs use an equal-area projection of the orientation sphere and display pole densities in multiples of the random distribution (=1 m.r.d.), where values above the random distribution display an increase of the preferred orientation (Wenk, 2006).

\subsection{Seismic anisotropies from LPO data}

For single crystals, seismic velocities can be calculated from the elastic stiffness tensors, as described in Babuska and Cara (1991). In polycrystalline rocks, single crystal tensors can be used to calculate the rock stiffness tensor ("single-crystal") by averaging with respect to the modal amount of the minerals (Mainprice, 1990; Lloyd et al., 2011; Mainprice et al., 2011). In practice, a rock is considered to be the sum of multiple single crystals, one for each mineral phase, with random orientations. Alternatively, by using the stiffness tensors averaged by ODFs, as obtained by the quantitative texture analysis ("ODF"), the stiffness tensor of an entire rock can be calculated. Although various averaging procedures can be adopted (e.g., Mainprice and Humbert, 1994), we used the arithmetic mean of the Voigt and Reuss bounds (Hill, 1952). Seismic velocities were calculated with the Beartex software (Wenk et al., 1998) using the ODFs obtained from the Rietveld refinement as inputs. Appropriate mineral single-crystal elastic constants were used, namely, biotite (Aleksandrov and Ryzhova, 1961), white mica (Vaughan and Guggenheim, 1986), K-feldspar (Hearmon, 1984; Bass, 1995), albite (Aleksandrov and Ryzhova, 1961) and quartz (Hearmon, 1984). Seismic properties are given as contoured stereographic projections, i.e., the pole figures, of the P-wave velocities (Vp).

\section{Results}

\subsection{Texture analysis}

The largest Volume Of Interest (VOI), not including the outer surfaces, was cut from the SXR- $\mu \mathrm{CT}$ dataset, resulting in a VOI measuring 307'416'434 voxels. We use VOI rather than the Representative Elementary Volume (REV), because the heterogeneities of the sample prevent the REV from being statistically meaningful for the whole sample. Hence, the VOI should be considered to be only qualitatively representative of the whole rock. Given that the sample was characterized both with diffraction and 
microtomography, we were able to separate the phengitic mica, the biotite, and the "denser" (highly absorbing) minerals, given their significantly different absorption contrast values (Fig. 5). Two binary volumes containing phengitic mica and biotite were created after the segmentation process via a manual thresholding process in the ImageJ software (Abramoff et al., 2004). Quartz and feldspar grains could not be effectively distinguished partially because their grain boundaries lacked sufficient occurrences of denser minerals that would have highlighted those boundaries.

The two binary volumes with the micas were used for the morphometric analysis of the two phases, and filtering was not necessary as a result of the high quality of the dataset, which exhibited low noise levels. This outcome was useful be minimizing the filtering when dealing with small objects such as the mica grains, because they can contribute to the orientations of single objects, avoids generating artefacts (Zandomeneghi et al., 2010). Based on the top images, it is possible to visually appreciate the texture of the sample and the sufficient separation of the two mica phases within the volume. A first analysis used the Blob3D software (Ketcham, 2005a, 2005b), mainly to obtain the morphometric parameters of the two distinct classes of objects. The single mica particles were separated using a semi-automatic separation procedure based on the erosion and dilation features present in the software. This procedure does not separate and measure the "single crystals" as a diffraction-based method would but instead manages single particles that may be one or more crystallites. This approach can also provide information about the aggregation of some phases, and highlight and quantify features that are not visible when using diffraction-based methods (e.g., lineation in phyllosilicates, as shown later). After separation, we used the approach described in

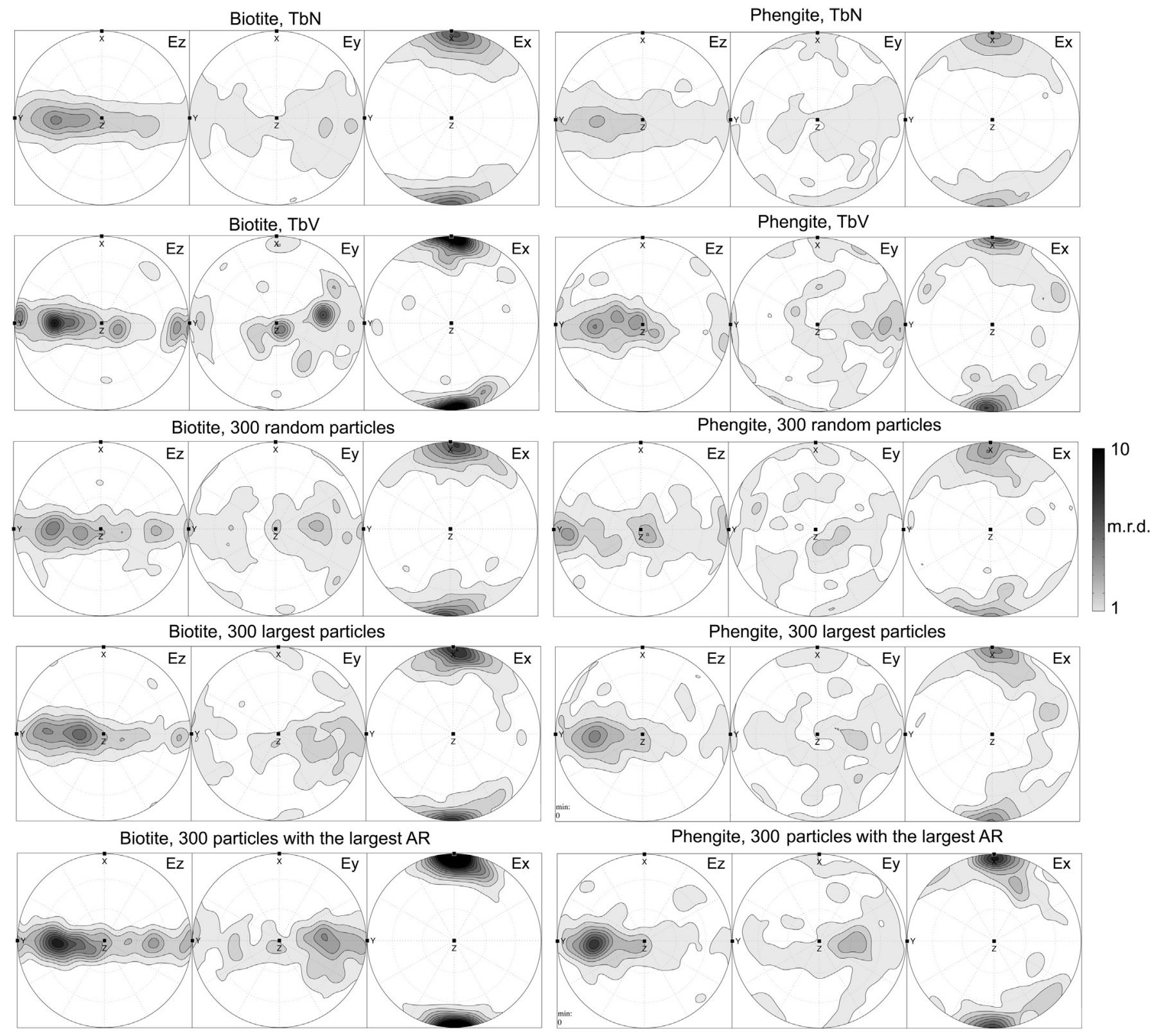

Fig. 7. SPO PF's for biotite and phengite in the sample. We have plotted the global "Texture by Volume" (TbV) and "Texture by Number" (TbN) PF's, plus the PF of 300 random, largest, or higher aspect-ratio (AR) objects to highlight any eventual correlation between preferred orientation and morphometric parameters. Coordinate system is as in Fig. 4. Ex, Ey and Ez are the three axes characterizing the orientation of a single objects, maximum, medium, and short axis, respectively. 
Voltolini et al. (2011a), based on a customised series of Matlab scripts and relying on the MTEX toolbox (Hielscher and Schaeben, 2008), to obtain the ODFs for the two micas. After, we plotted the PFs of the three axes characterising the orientation of individual objects (where Ex, Ey, Ez are the maximum, medium, and short axis, respectively). This procedure allows for SPO quantification and can provide pole figures, so it can be directly compared with the LPO obtained from the neutron diffraction measurements. The comparison should account for the fact that the shape of the object is fitted with an ellipsoid, so the symmetry of the mica particles is orthorhombic, while the crystallographic symmetry in mica mineral is monoclinic. For this reason, the basal crystallographic planes, (001) considering a 2nd setting unit cell description, can be easily correlated to the Ez axes obtained from the SPO analysis. A similar correlation is very difficult to establish for the other crystallographic directions because the correlation between the crystallographic plane and the shape is not direct.

The results of the analysis are also provided as plots of particle size (plotted as volumes) distributions for the two different micas (Fig. 6a). These plots show that the two size distributions are similar. However, the distribution plot of the aspect-ratios of the different mica particles because the biotite particles have greater aspect ratios than the phengitic micas (Fig. 6b). Size and aspectratio distributions are important parameters for identifying any eventual correlations with the SPO. With respect to the latter, we found 1789 valid objects (i.e., as defined by a sufficiently large number of voxels and not cut by the surfaces of the VOI) to calculate the ODF for biotite. Similarly, we found 2080 for phengitic mica. Because the procedure used to calculate the ODF for the SPO is strictly related to that used for EBSD, the statistical reliability should be correlated as well. Therefore, we expect rather reliable results, given the number of objects studied (e.g., see Bozzolo et al., 2007; Matthies and Wagener, 1996), which is larger than that usually found in studies based on EBSD. The procedure provided the PFs and they show that the shape of the texture is extremely similar for both micas, although biotite shows a stronger preferred orientation, as shown by highest density values of the Ex axes for biotite then mica parallel to the lineation (Fig. 7). TbN is the "Texture by Number", where each object has the same weight in building the ODF, TbV is the "Texture by Volume" and each object orientation weight is proportional to the object volume. Considering all sample sets (Fig. 7, Table 2), the lineation is very evident in the $\mathrm{N}-\mathrm{S}$ direction in Ex PFs, whereas the foliation is evident in the Ez PFs.

Considering the diffraction-derived data, the resultant LPOs have main reliability factors for the quantitative texture analysis based on Chateigner (2005), which was used to assess the quality of the refinement and the reliability of the obtained ODF (Figs. 8 and 9, and Table 3). The represented lattice planes are those recalculated using the ODF.

\subsubsection{Quartz}

$<\mathrm{c}>$ axes describe girdle distributions that are asymmetrically oriented with respect to the lineation direction (Fig. 8). Moreover, the $<a>$ axes display the distribution of the maxima widely described for quartz deformation at low temperatures under a simple shear regime (e.g., Unzog and Kurz, 2000; Stipp et al., 2002; Passchier and Trouw, 2005; Otani and Wallis, 2006) (Fig. 8).

\subsubsection{K-feldspar}

K-feldspar does not display a LPO, although the $<\mathrm{c}>$ axes cluster at high angles relative to the lineation direction, close to $Z$ (Fig. 8). Additionally, several isolated secondary maxima are well defined (Fig. 8), and the $<\mathrm{a}>$ and axes define girdles containing the lineation direction, commonly at low angles relative to the $\mathrm{XY}$ plane (Fig. 8).

\subsubsection{Albite}

The $<\mathrm{a}>$ axes of albite define a girdle containing the lineation direction with two maxima, one oriented parallel or close to the lineation direction and one parallel to Y (Fig. 8). The axes describe a girdle distribution at high angles with the lineation, containing $Y$ and $\mathrm{Z}$ directions, with the strongest maxima close to $\mathrm{Z}$, whereas the $<c>$ directions show a girdle distribution at high angle to the lineation and weak maxima at high angle to the lineation and about $30^{\circ}$ to $\mathrm{Z}$ (Fig. 8 ).

\subsubsection{Micas}

Biotite and phengite display similar textures, which are characterised by a girdle distribution of the $<\mathrm{c}>$ axes that is perpendicular to the lineation direction (Fig. 9). The girdle distribution is asymmetric and characterised by elongated maxima that are more pronounced in the right portion of the pole figures (Fig. 9). The axes cluster parallel to the macroscopic lineation, while the $<a>$ axes display less pronounced maxima with a weak girdle containing the lineation direction (Fig. 9).

\subsection{Seismic velocities}

Quantitative LPO of rock-forming minerals, as derived by neutron diffraction analysis, is here used to calculate elastic parameters of the LM1 sample. The comparison of LPO-derived seismic anisotropies versus the single crystal-derived ones is used to estimate the influence of the LPO anisotropies on seismic velocity as a function of direction.

The comparison of the Vp for the "Single crystal" and "ODF" (Tatham et al., 2008; Lloyd et al., 2011; Mainprice et al., 2011) (Fig. 10 and Table 4) shows that the seismic velocities are characterised by strong anisotropies that are better developed in the "single crystal" systems where lattice anisotropies prevail. The "ODF" velocities still show anisotropies, although these values are less pronounced as shown in Fig. 10 where greatest values for ODFderived $\mathrm{Vp}$ are smaller than single crystal-derived of $0.8-2 \mathrm{~km} / \mathrm{s}$. In detail, the biotite and phengitic mica Vp single crystals are characterised by the greatest velocities parallel to the $<\mathrm{a}>$ and axes, whereas the slowest values fall parallel to the $<\mathrm{c}>$ axis. When the lattice ODF is considered, the fastest direction becomes parallel to the mesoscopic lineation ( $X$ direction), and the slowest is perpendicular to the $X Y$ plane. Biotite and phengitic mica display comparable $\mathrm{Vp}$ patterns, although their absolute values differ because the phengitic mica $\mathrm{Vp}$ velocities are less as this phase is already in the single crystal setting. However, in K-feldspar, albite and quartz, although characterised by high anisotropies due to their respective crystal structures, such pronounced differences are absent.

Similar anisotropies are also described by the $\mathrm{Vp}$ anisotropy,

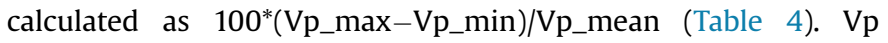
anisotropy is greater by a factor of more than three in single crystals as compared to the lattice ODF Vp, which is particularly true in Kfeldspar, albite and quartz (Fig. 10 and Table 4) where the difference between maximum and minimum velocities is between 1 and $3.3 \mathrm{~km} / \mathrm{s}$. The whole-rock averaged velocities show similar relations between the single crystal and ODF values of $\mathrm{Vp}$. The first is in the order of $1 \mathrm{~km} / \mathrm{s}$ and the second $0.2 \mathrm{~km} / \mathrm{s}$. For example, although the distribution of $\mathrm{Vp}$ in the single crystal setting is controlled by the feldspar and albite Vp distribution, by contrast in the ODF-based analysis, the distribution is controlled by the biotite and phengitic mica Vp anisotropy. For the latter, the fastest Vp are directed parallel to the $X$ direction of lineation or close to the $Y$ direction. 
Table 2

Shape preferred orientation parameters.

\begin{tabular}{|c|c|c|c|c|c|c|c|}
\hline \multirow[t]{2}{*}{ Sample label } & \multicolumn{2}{|l|}{ Ez PF } & \multicolumn{2}{|l|}{ Ey PF } & \multicolumn{2}{|l|}{ Ex PF } & \multirow[t]{2}{*}{ F2 } \\
\hline & $\begin{array}{l}\text { Max } \\
\text { [m.r.d] }\end{array}$ & $\begin{array}{l}\text { Min } \\
\text { [m.r.d] }\end{array}$ & $\begin{array}{l}\text { Max } \\
{[\mathrm{m} . \mathrm{r} . \mathrm{d}]}\end{array}$ & $\begin{array}{l}\text { Min } \\
\text { [m.r.d] }\end{array}$ & $\begin{array}{l}\text { Max } \\
{[\mathrm{m} . \mathrm{r} . \mathrm{d}]}\end{array}$ & $\begin{array}{l}\text { Min } \\
\text { [m.r.d] }\end{array}$ & \\
\hline Bt TbN (1789 obj) & 5.35 & 0.03 & 2.26 & 0.37 & 7.22 & 0.08 & 3.22 \\
\hline Bt TbV & 10.12 & 0.01 & 8.13 & 0.13 & 13.49 & 0.03 & 9.06 \\
\hline Bt 300 random & 5.93 & 0.00 & 3.32 & 0.02 & 8.17 & 0.01 & 4.11 \\
\hline Bt 300 largest & 6.64 & 0.00 & 2.78 & 0.03 & 9.05 & 0.02 & 4.72 \\
\hline Bt 300 max AR & 9.82 & 0.00 & 5.15 & 0.00 & 17.52 & 0.00 & 10.01 \\
\hline Ph TbN (2080 obj) & 3.30 & 0.23 & 1.81 & 0.55 & 4.18 & 0.27 & 1.72 \\
\hline $\mathrm{Ph}$ TbV & 5.10 & 0.06 & 4.00 & 0.26 & 8.09 & 0.12 & 3.27 \\
\hline $\mathrm{Ph} 300$ random & 4.52 & 0.00 & 2.80 & 0.18 & 5.03 & 0.03 & 3.11 \\
\hline Ph 300 largest & 5.54 & 0.01 & 2.72 & 0.14 & 5.20 & 0.01 & 3.06 \\
\hline $\mathrm{Ph} 300$ max AR & 8.76 & 0.00 & 3.85 & 0.03 & 9.34 & 0.00 & 5.08 \\
\hline
\end{tabular}

$\mathrm{TbN}=$ Texture-by-Numbers; $\mathrm{TbV}=$ Texture-by-Volume (see text); AR = Aspect Ratio; Ex, Ey, Ez are the maximum, medium, and short axis, respectively; m.r.d. = multiple of random distribution

However, the Vp anisotropies for the single crystal setting are more than three times that in the ODF setting.

\section{Discussion}

\subsection{Shape and lattice preferred orientation}

The SPO and LPO analyses describe a strong mineral lineation marked by biotite and phengite that is invariably parallel to the mesoscopic lineation in the $X$ direction. As shown by the statistical analysis of the mesoscopic orientation data (Fig. 2), the distribution is characterised by a strong single direction ( $X$ axis). Additionally, a prolate distribution of the linear fabrics was confirmed by the SPO analysis of biotite and phengite grains, because the biotite SPO distribution is highly prolate with the $X$ direction as its principal axis of symmetry, and the Ex major axes also clustering close to this direction (Fig. 7). A similar geometry is described by the c-axis of biotite and phengite, which defines a cluster distribution that falls close to the same $X$ direction (Fig. 9). This feature is commonly linked with a weak b-axis girdle distribution that resides close to the $X Y$ foliation plane. As discussed in the introduction, these relations are not attainable in LPO studies involving phyllosilicates (see Wenk et al., 2010), but here we demonstrate that the combined SPO-LPO approach successfully produces data relating the lattice geometry with the mesoscopic and microscopic preferred shape orientations. This outcome is especially useful where the textural features are not related to specific crystallographic directions, for example, the lineation in phyllosilicates can be unrelated to any specific crystallographic direction. Furthermore, diffraction-based methods would not see such textural features, where tomography-based SPO analysis can easily see and quantify this type of feature in detail. The correlation of LPO to SPO would be very difficult to obtain with SEM or optical microscopy techniques. Yet, such approaches cannot yield information from within the same sample, nor typically provide data in a digitally and spatially registered for easy formatting and comparison.

The combined approach was also useful for studying the influence of the size and aspect ratio of the mica particles. For this purpose, three series of PFs using 300-member populations of random objects, largest objects and objects with the largest aspect ratio were plotted (Fig. 7) and the largest mica crystals do not appear to be more preferentially oriented in the sample than the

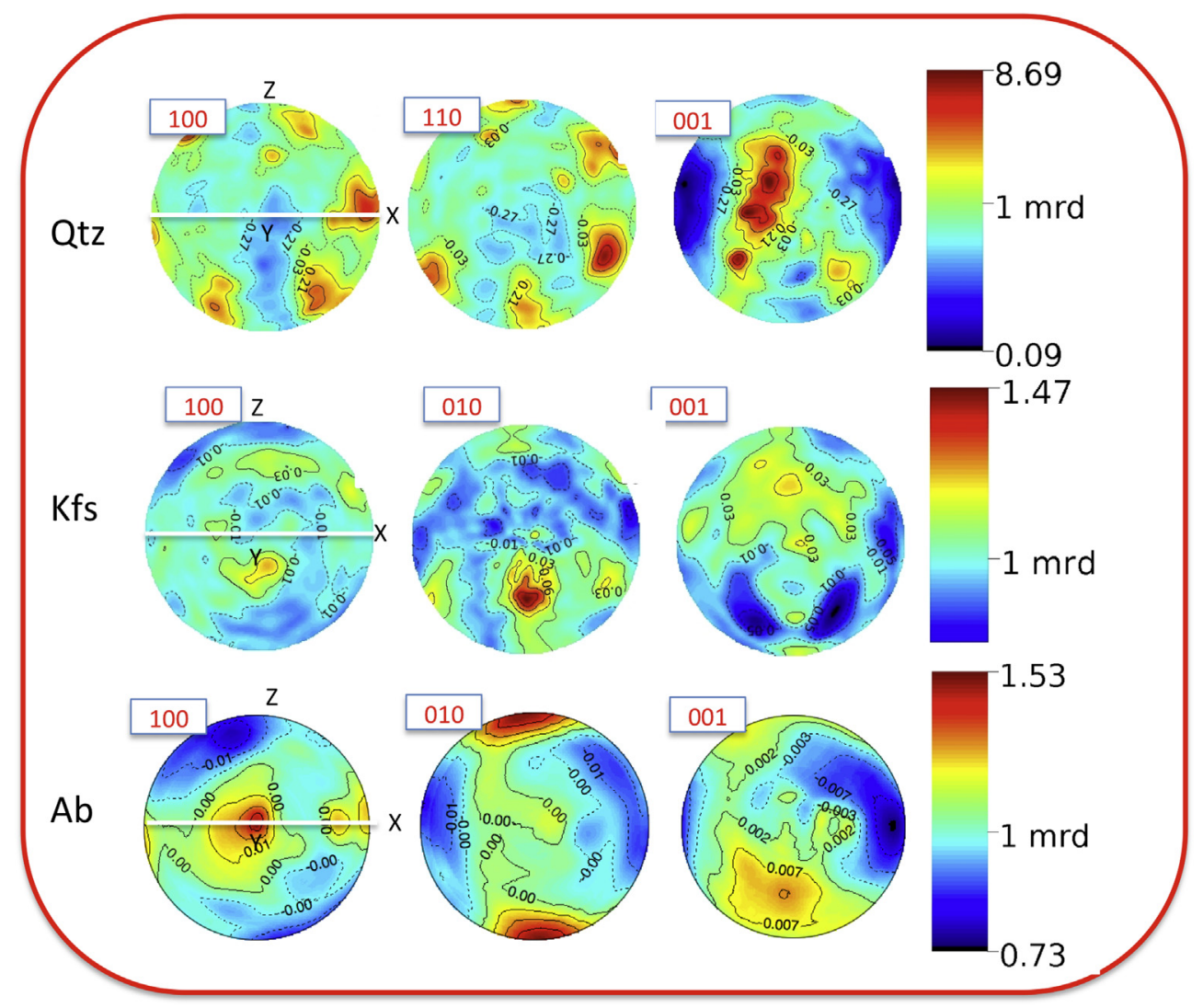

Fig. 8. Contoured stereographic projections of pole figures, representing main crystallographic planes orientations of quartz (Qtz), K-feldspar (Kfs) and albite (Ab) recalculated from ODF (see text). Orientation densities are expressed as multiple of the random distribution (m.r.d.). X, Y, $Z$ as defined in Fig. 4. 


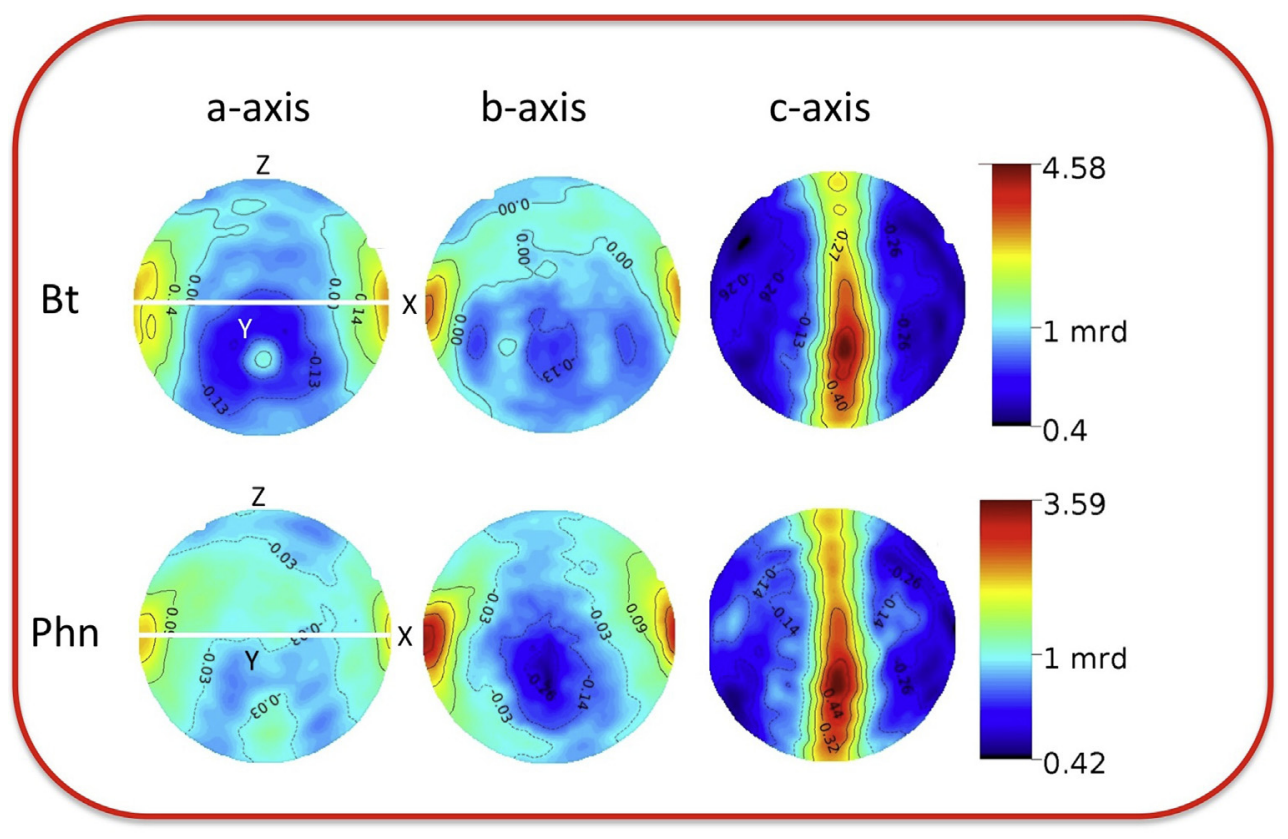

Fig. 9. Contoured stereographic projections, pole figures, representing main crystallographic planes orientations of biotite (Qtz) and phengite (Phn) recalculated from ODF (see text). Orientation densities are expressed as a multiple of random distribution (m.r.d.). $X, Y, Z$ are as defined in Fig. 4.

smaller ones. This characteristic is shared by both mica species, where regardless of their aspect ratio, the longest axis is approximately parallel to the lineation. In non-coaxial settings is commonly expected that the most elongate grains show an orientation closest to the flow plane (e.g. Shelley, 1995). Conversely, mica SPO and LPO in LM1 sample is orthorhombic, which is not common in a shear zone, where either a monoclinic or triclinic symmetry is typically described or expected (e.g., Passchier, 1998; Iacopini et al., 2007). This symmetry is commonly explained as resulting from the sample being located in a rock volume where pure shearing dominated (e.g., Gapais and Cobbold, 1987; Passchier and Trouw, 2005) so that most mica deformation occurred as a result of passive rotation, although it can also occur in the core region under a simple shear setting, as described by Spalla and Zucali (2004). Alternatively, mica with strong SPO and LPO parallel to the shear direction may also be expected in rigid objects flowing within a soft matrix in a non-coaxial flow (e.g., ten Grothenius et al., 2002). However, in our example, the mylonitic fabrics relate to the Alpine collision (e.g., D2 deformation in Froitzheim, 2001). For this setting, simple shearing kinematics were described (e.g. Lacassin, 1987; Keller and Schmid, 2001) and dynamic recrystallization of mica was inferred by microstructural and petrographic analysis (Keller et al., 2005). Consequently, the local- to regional-scale deformation history constrains the strain pattern to a bulk simple-shear, though microscale partitioning occurs, as for example in the mica-rich layers. This interpretation is supported by the LPO analysis of quartz, which exhibits a LPO up to 8.70 m.r.d. This value results from intracrystalline deformation, as suggested by the microstructural features (Fig. 3) and by the typical LPO patterns of the a-, $\mathrm{m}$ - and c-axes (Fig. 8). The latter also suggests the presence of a strong non-coaxial component of the deformation (Sullivan, 2013). The reconstructed LPO of quartz shows a monoclinic symmetry in which the fabric axes are indicative of prism $<\mathrm{a}>$ slip as the active slip system (e.g., Unzog and Kurz, 2000; Pleuger et al., 2009). The same LPO distribution in quartz is widely used as kinematic criteria for inferring the shear sense, assuming simple shear (Bouchez, 1978; Lister and Hobbs, 1980). Moreover, the development of c-axis cluster around $\mathrm{Y}$ has been interpreted as indicative of increasing strain (e.g., Schmid and Casey, 1986; Law, 1990; Unzog and Kurz, 2000) within a non-coaxial strain pattern (Law. 1990). This constraint, together with the regional scale kinematics, is used to characterize the general strain pattern, accounting for the influence of mica content on quartz LPO being low (Joy and Saha, 1998), even though grain-boundary sliding may occur at the quartz-mica contact, likely lowering the fabrics strength. In addition, albite LPO distributions, in agreement with recent observations and simulations on anorthosite (Barreiro et al., 2007) and with common features described for plagioclase deforming at medium to high-grade metamorphic conditions (Passchier and Trouw, 2005) where [100] axes are close to the lineation, suggest the deformation of albite occurred under simple shear setting. Moreover, the monoclinic symmetry between [100] axes and the lineation direction support this interpretation and the general shear setting of the LM1 sample, confirming the different behaviour of quartz and feldspar with respect to mica layers. While deforming simultaneously and maintaining continuity at the lattice scale, the mica-rich and quartz + feldspar-rich layers deformed differently.

Table 3

Principal reliability factors for LPO analysis: single phase factors are $\mathrm{Rw}=$ weighted, $\mathrm{Rb}=$ Bragg-like profile factors, $\mathrm{F} 2=$ Texture index; global factors are $\mathrm{Rw}=$ weighted, $\mathrm{Rb}=$ Bragg-like, GoF = Goodness of Fit.

\begin{tabular}{|c|c|c|c|c|c|c|}
\hline \multicolumn{2}{|c|}{ Mineral phase Cell parameters } & \multicolumn{3}{|c|}{$\begin{array}{l}\text { Single phase } \\
\text { factors }\end{array}$} & \multicolumn{2}{|c|}{ Global factors } \\
\hline & & $\mathrm{F} 2$ & Rw & $\mathrm{Rb}$ & GoF Rw & $\mathrm{Rb}$ \\
\hline Muscovite & $\begin{array}{l}a=5.18, b=8.96 \\
c=20.1 ; \text { beta }=95.66\end{array}$ & 1.45 & 26 & 16 & 3.0531 .02 & 24.68 \\
\hline Biotite & $\begin{array}{l}a=5.31, b=9.22 \\
c=10.09 ; \text { beta }=100.2\end{array}$ & 8.66 & 32 & 31 & & \\
\hline Albite & $\begin{array}{l}a=8.17, b=12.85 \\
c=14.17 ; \text { alpha }=93.17 \\
\text { beta }=115.95, \text { gamma }=91.22\end{array}$ & 1.3 & 39 & 29 & & \\
\hline K-feldspar & $\begin{array}{l}a=8.75, b=12.67 \\
c=6.94 ; \text { beta }=113.42\end{array}$ & 1.04 & 24 & 18 & & \\
\hline Quartz & $a=4.90, c=5.37$ & 15.23 & 25 & 15 & & \\
\hline
\end{tabular}



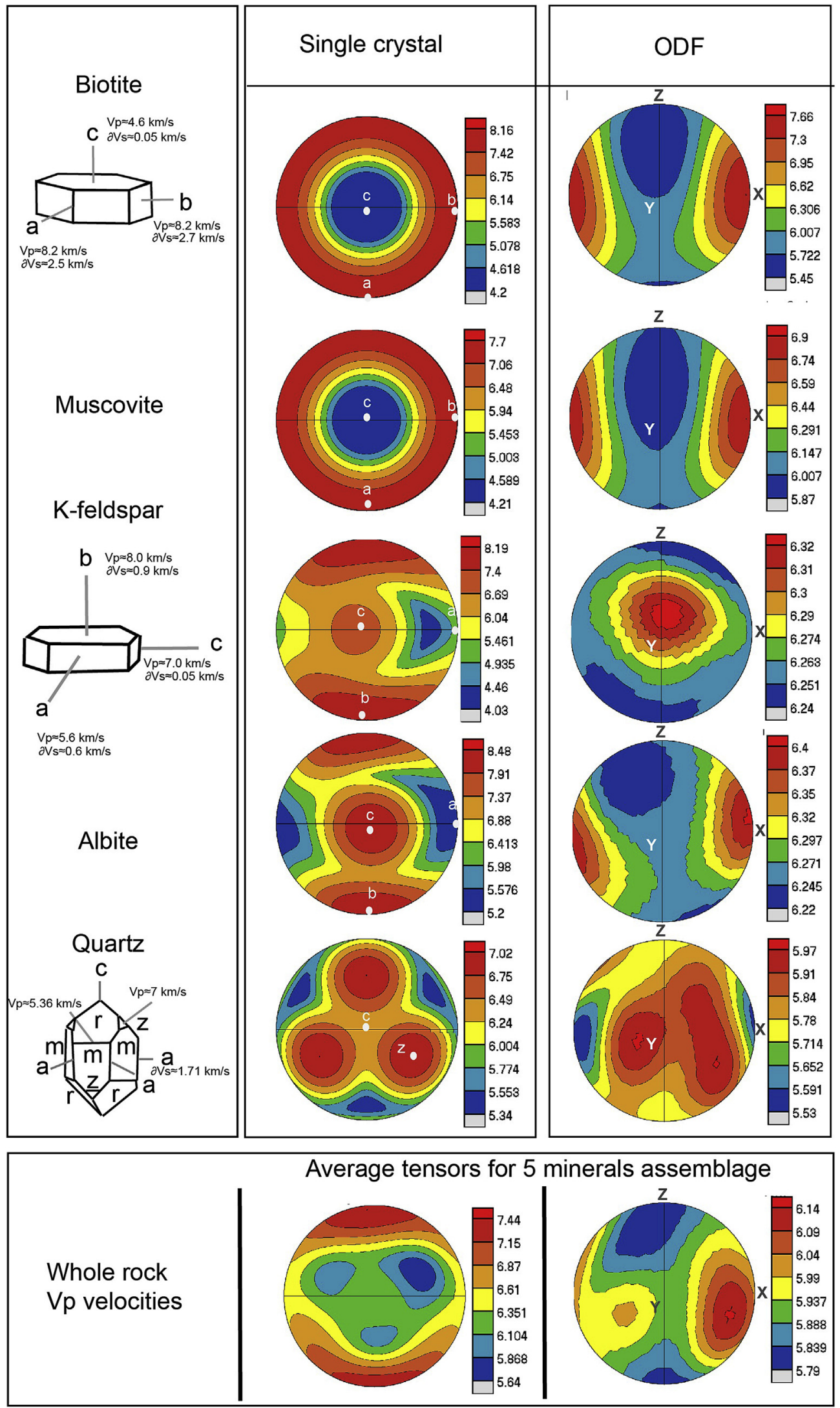

Fig. 10. Principal Vp seismic velocities directions of LM1 rock-forming minerals: single crystals column corresponds to Vp calculated on the basis of single-crystal elastic stiffness tensor, whereas in the ODF column Vp are calculated by the elastic stiffness tensor homogenized using the calculated ODF for each mineral phase. In the last row, the corresponding single crystals Vp are averaged using Voigt averaging (e.g., Mainprice et al., 2011). 
Table 4

Comparison of calculated seismic Vp velocities, from single crystal tensor, ODF from LPO analysis; Vp anisotropies $=100 *(\mathrm{Vpmax}-\mathrm{Vpmin}) / \mathrm{Vpmean}$ from single crystal and ODF averages.

\begin{tabular}{|c|c|c|c|c|c|c|}
\hline \multirow[t]{2}{*}{ Phase } & \multicolumn{2}{|c|}{ Single crystal } & \multicolumn{2}{|l|}{ ODF } & \multicolumn{2}{|c|}{$\begin{array}{l}\text { Vp } \\
\text { anisotropy } \\
100^{*}(\text { Vpmax } \\
\text { - Vpmin)/ } \\
\text { Vpmean }\end{array}$} \\
\hline & $\operatorname{Min}(\mathrm{Vp})$ & $\operatorname{Max}(\mathrm{Vp})$ & $\operatorname{Min}(\mathrm{Vp})$ & $\operatorname{Max}(\mathrm{Vp})$ & Single & ODF \\
\hline $\mathrm{Bt}$ & 4.20 & 8.10 & 5.45 & 7.70 & 63 & 34 \\
\hline Wm & 4.20 & 7.70 & 5.80 & 6.90 & 59 & 17 \\
\hline Kfs & 4.03 & 8.20 & 6.24 & 6.35 & 68 & 2 \\
\hline $\mathrm{Pl}$ & 5.18 & 8.48 & 6.19 & 6.42 & 48 & 4 \\
\hline Qtz & 5.30 & 7.31 & 5.53 & 5.99 & 32 & 8 \\
\hline Whole rock & 5.60 & 7.50 & 5.70 & 6.16 & 29 & 8 \\
\hline
\end{tabular}

Calculated seismic velocities ( $\mathrm{Vp}$, in $\mathrm{km} / \mathrm{s}$ ).

\subsection{L-fabric development and $3 D$ quantitative analysis}

Spatial variation of lithology and the related changes in mechanical properties may have been a primary mechanism controlling the development of the $\mathrm{L}$ fabric during mylonite formation in the Monte Rosa unit. Sullivan (2013 and references therein) predicts the formation of $\mathrm{L}$ fabrics in constrictional strain kinematic settings. Most structures and crystallographic fabrics used to infer true constrictional deformation (Sullivan, 2013) are recognised in the Monte Rosa sample using the proposed technique. Mineral shape fabrics: i) The basal cleavage traces of the micas are randomly oriented, whereas the [001] direction resides perpendicular to the lineation (Fig. 3); ii) the compositional segregation of quartzofeldspathic domains occurs with separation by mica-rich domains (Figs. 2, 3 and 5); and iii) no grain-shape preferred orientation exists in lineation-normal sections (Fig. 5), whereas the characters of lattice deformation and dynamic recrystallisation are abundant (Fig. 3 and text). Crystallographic fabrics: i) The quartz c- and a-axes fabrics (Fig. 8), and in particular the characteristic a-axis double girdle (Fig. 8) are good indicators of the finite strain geometry for rock that has experienced non-coaxial deformation (Sullivan and Beane, 2010); ii) the girdle poles to (001) of biotite and phengite (Fig. 9) are geometries expected for constrictional deformation (Ramsay and Huber, 1983; Sullivan and Beane, 2010); and iii) the poles to the $\mathrm{a}$ - and $\mathrm{b}$-axes cluster parallel to the mesoscopic lineation (e.g., Compton, 1980). Combining the above characteristics, we argue that the mylonitic lineated fabric developed during constrictional non-coaxial deformation. We believe that this state was attained during collisional stages because kinematic and tectonometamorphic studies suggest a simple-shear pattern active at that time (Keller et al., 2005). According to Lacassin (1987), ENE trending deformation may be associated with back-thrusting, which is kinematically compatible with the described development of the Ragno fold (Fig. 1) and mylonitic lineation in the LM1 sample, thereby accommodating vertical displacements along the Insubric Line system.

\subsection{Seismic anisotropies}

SPO and LPO fabrics can strongly influence the seismic anisotropy of a rock (Lloyd et al., 2011), minerals is highly influenced by both LPO and SPO anisotropies. Such a relation is found in our sample not only for single phases but also for the whole rock. Whole rock $\mathrm{Vp}$ anisotropy falls mostly parallel to the lineation direction (Fig. 11) and is influenced primarily by biotite and phengite LPOs and, in particular, by the directions of the a- and b-axes for both micas. The $\mathrm{Vp}$ anisotropy is also characterised by a girdle that resides broadly parallel to the foliation plane ( $X Y$ plane) with a secondary maximum, controlled by the quartz LPO, of a strong Vp anisotropy close to the $Y$ direction. The contribution to the overall anisotropy by K-feldspar and albite LPO is less important due to the relatively small amounts of these minerals at approximately $15 \%$ by vol. and their weak texture (Figs. 8 and 9 and Table 3).

According to Siegesmund et al. (1991) and Wendt et al. (2003), the distribution of grain boundaries (3D) is closely related to Vp anisotropies, as for example, having the fastest $\mathrm{Vp}$ runs parallel to the grain boundaries. This observation, applied to the biotite and phengite of the LM1 sample, correspond to a Vp increase along the plane defined by the Ex axis and the preferred directions, plunging between the $\mathrm{Ez}$ and $\mathrm{Ey}$ axes, in both the biotite and phengite (Fig. 7).

\section{Conclusions}

A $1 \mathrm{~cm}^{3}$ sample of mylonitized granite from the Monte Rosa unit, Central-Western Italian Alps, where the 3D fabric was investigated by a combination of neutron diffraction and SXR- $\mu$ CT.

- We demonstrate that the combined SPO-LPO approach successfully produces data relating the lattice geometry with the mesoscopic and microscopic fabrics, especially useful for cases in which the textural features are not related to specific crystallographic directions, for example, the lineation in phyllosilicates.

- The combination of 3D SPO and LPO data permits the L tectonite fabric to be reconstructed in terms of its kinematic geometry,
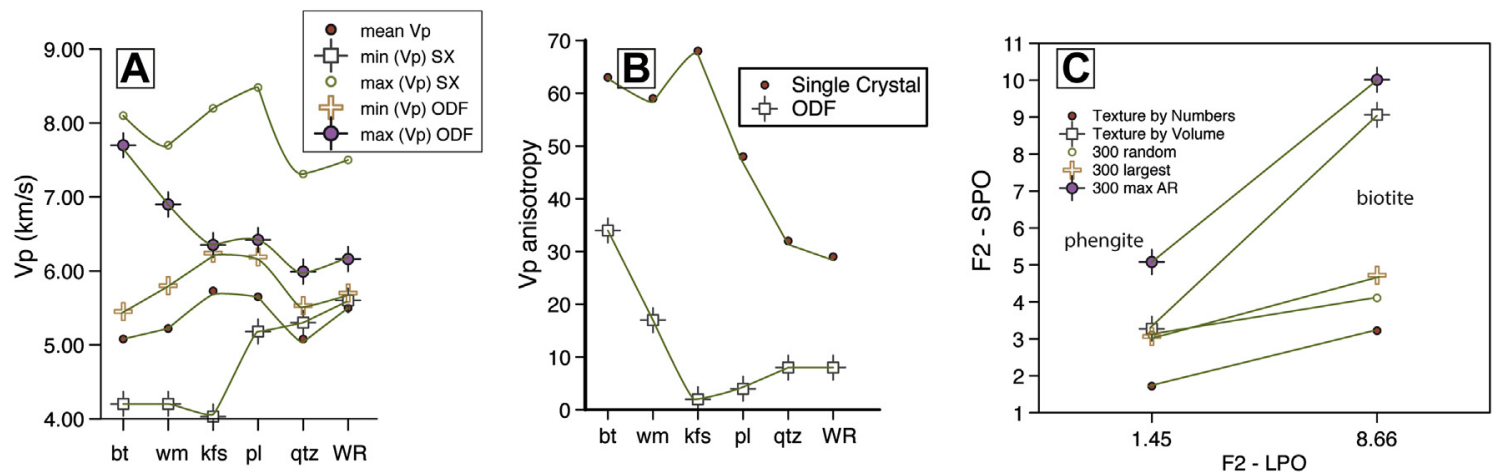

Fig. 11. A) Plot of Vp velocities calculated by single crystal and ODF; (B) Vp anisotropy plot for every mineral phase calculated for the single crystal stiffness tensor or the ODF homogenized stiffness tensor; $\mathrm{C}$ ) comparison of the $\mathrm{F}^{2}$ texture indexes calculated for shape (F2-SPO) and lattice (F2-LPO) ODFs. 
constrictional non-coaxial strain state and the associated high viscosity contrasts at the $\mathrm{km}$-scale.

- Because the calculated ODFs are derived from the same sample, which is relatively large in size (approximately $1 \mathrm{~cm}^{3}$ ), the results may be considered at larger scale and applied to calculate other material properties, such as the magnitudes and directional variability of seismic velocities.

- This procedure can be applied to any rock or generic solid sample for which complete 3D fabric data are required, including voids and discontinuities.

\section{Acknowledgments}

The authors thank Bill Dunne for editorial handling and careful and encouraging review, William Carlson and Florian Fusseis for their reviews. This work benefitted from discussion with Guido Gosso and his review of early version.

\section{Appendix A. Supplementary data}

Supplementary data related to this article can be found at http:// dx.doi.org/10.1016/j.jsg.2014.02.011

\section{References}

Abramoff, M.D., Magelhaes, P.J., Ram, S.J., 2004. Image processing with ImageJ. Biophot. Int. 11 (7), 36-42.

Aleksandrov, K.S., Ryzhova, T.V., 1961. The elastic properties of rock-forming minerals, II: layered silicates: Izv, vol. 12. Acad. Sci. USSR, Geophys. Ser, pp. 186-189.

Artioli, G., 2007. Archeometria ed archeologia. In: il fascino di un amore difficile: Riv. Archeol, vol. 31, pp. 207-209.

Babuska, V., Cara, M., 1991. Seismic Anisotropy in the Earth. Springer.

Baker, D.W., Wenk, H.R., 1972. Preferred orientation in a low-symmetry quartz mylonite. J. Geol. 80 (1), 81-105.

Baker, D.R., Mancini, L., Polacci, M., Higgins, M.D., 2012. An introduction to the application of X-ray microtomography to the three-dimensional study of igneous rocks. Lithos, 262-276.

Barreiro, J.G., Lonardelli, I., Wenk, H.R., Dresen, G., Rybacki, E., Ren, Y., Tomé, C.N., 2007. Preferred orientation of anorthite deformed experimentally in Newtonian creep. Earth Planet. Sci. Lett. 264 (1), 188-207.

Barreiro, J.G., Catalán, J.R.M., 2012. The Bazar shear zone (NW Spain): microstructural and time-of-flight neutron diffraction analysis. J. Virtual Explor. 41, 5. http://dx.doi.org/10.3809/jvirtex.2011.00296.

Bass, J.D., 1995. Elasticity of Minerals, Glasses, and Melts. In: AGU Reference Shelf, vol. 2, pp. 45-63.

Bigi, G., Castellarin, A., Coli, M., Dal Piaz, G.V., Sartori, R., Scandone, P., Vai, G.B., 1990. Structural Model of Italy. Sheets 1-2: CNR, Progetto Finalizzato Geodinamica.

Borghi, A., Compagnoni, R., Sandrone, R., Schmid, S., Froitzheim, N., Heilbronner, R. Stuenitz, H., 1996. Composite P-T paths in the internal Penninic massifs of the Western Alps; petrological constraints to their thermo-mechanical evolution. Eclogae Geol. Helvetiae 89 (1), 345-367.

Bouchez, J.L., 1978. Preferred orientations of quartz axes in some tectonites: kinematic inferences. Tectonophyiscs 49, 25-30.

Bozzolo, N., Gerspach, F., Sawina, G., Wagner, F, 2007. Accuracy of orientation distribution function determination based on EBSD data-A case study of a recrystallized low alloyed Zr sheet. J. Microsc. 227 (3), 275-283.

Brun, F., Mancini, L., Kasae, P., Favretto, S., Dreossi, D., Tromba, G., 2010. Pore3D: software library for quantitative analysis of porous media: nuclear instruments and methods in physics research section A. Accel. Spectrom. Detect. Assoc. Equip. 615 (3), 326-332.

Bunge, H.J., Esling, C., 1982. Quantitative Texture Analysis, pp. 551.

Cavallo, A., Bigioggero, B., Colombo, A., Tunesi, A., 2004a. The beola: a dimension stone from the Ossola valley (NW Italy). Per. Mineral. 73 (3), 85-97.

Cavallo, A., Bigioggero, B., Colombo, A., Tunesi, A., 2004b. The Verbano Cusio Ossola province: a land of quarries in northern Italy (Piedmont). Per. Mineral. 73 (3), $197-210$

Chateigner, D., 2005. Reliability criteria in quantitative texture analysis with experimental and simulated orientation distributions. J. Appl. Crystallogr. 38, 603-611.

Chateigner, D., Hedegaard, C., Wenk, H.R., 2000. Mollusc shell microstructures and crystallographic textures. J. Struct. Geol. 22 (11-12), 1723-1735.

Choukroune, P., Gapais, D., 1983. Strain pattern in the Aar granite (Central Alps): orthogneiss developed by bulk inhomogeneous flattening. J. Struct. Geol. 5 (3/ 4), 411-418.

Cloetens, P., Barrett, R., Baruchel, J., Guigay, J.P., Schlenker, M., 1996. Phase objects in synchrotron radiation hard X-ray imaging. J. Phys. Appl. Phys. 29, 133.
Cloetens, P., Pateyron-Salome, M., Buffiere, J.Y., Peix, G., Baruchel, J., Peyrin, F., Schlenker, M., 1997. Observation of microstructure and damage in materials by phase sensitive radiography and tomography. J. Appl. Phys. 81, 5878-5886.

Cobbold, P.R., Gapais, D., Means, W.D., Treagus, S.H., 1987. Shear criteria in rocks. Oxford-New York, International, Pergamon, 778 p.

Compton, R.R., 1980. Fabrics and strains in quartzites of a metamorphic core complex, Raft River Mountains, Utah. In: Crittenden Jr., M.D., Coney, P.J., Davis, G.H. (Eds.), Cordilleran Metamorphic Core Complexes, Geological Society American Memoir, vol. 153, pp. 271-279.

Dowd, B.A., Campbell, G.H., Marr, R.B., Nagarkar, V.V., Tipnis, S.V., Axe, L., Siddons, D.P., 1999. Developments in synchrotron X-ray computed microtomography at the National Synchrotron Light Source. SPIE's Int. Symp. Opt. Sci. Eng. Instrum., 224-236.

Engi, M., Scherrer, N.C., Burri, T., 2001. Metamorphic Evolution of Pelitic Rocks of the Monte Rosa Nappe: Constraints from petrology and single grain monazite age data. In: Schweizerische Mineralogische und Petrographische Mitteilungen, vol. 81 (3), pp. 305-328.

Fisher, N., Embleton, B.J.J., 1987. Statistical Analysis of Spherical Data. Cambridge University Press, p. 329.

Friedrich, J.M., Wignarajah, D.P., Chaudhary, S., Rivers, M.L., Nehru, C.E., Ebel, D.S. 2008. Three-dimensional petrography of metal phases in equilibrated L chondrites - effects of shock loading and dynamic compaction. Earth Planet. Sci. Lett. 275 (1), 172-180.

Froitzheim, N., 2001. Origin of the Monte Rosa nappe in the Pennine Alps - a new working hypothesis. Geol. Soc. Am. Bull. 113 (5), 604-614.

Gapais, D., Cobbold, P.R., 1987. Slip system domains; 2, kinematic aspects of fabric development in polycrystalline aggregates. Tectonophysics 138 (2-4), 289309.

Gasco, I., Borghi, A., 2011. PT Alpine metamorphic evolution of the Monte Rosa nappe along the piedmont zone boundary (Gressoney Valley, NW Italy). Lithos $127,336-353$.

Hearmon, R.F.S., 1984. The Elastic Constants of Crystals and Other Anisotropic Materials. In: Landolt-Börnstein Numerical Data and Functional Relationships in Science and Technology Group III, vol. 18. Springer-Verlag, Berlin.

Hielscher, R., Schaeben, H., 2008. A novel pole figure inversion method: specification of the MTEX algorithm. J. Appl. Crystallogr. 41 (6), 1024-1037.

Hill, R., 1952. The elastic behavior of a crystalline aggregate. Proceed. Phys. Soc Lond. 65, 351-354.

Howard, S.A., Preston, K.D., 1989. Profile fitting of powder diffraction patterns. Rev. Mineral. 20, 217-275.

Iacopini, D., Passchier, C.W., Koehn, D., Carosi, R., 2007. Fabric attractors in genera triclinic flow systems and their application to high strain shear zones: a dynamical system approach. J. Struct. Geol. 29 (2), 298-317.

Ismaîl, W.B., Mainprice, D., 1998. An olivine fabric database: an overview of upper mantle fabrics and seismic anisotropy. Tectonophysics 296 (1-2), 145-157.

Jerram, D.A., Higgins, M.D., 2007. 3D analysis of rock textures: quantifying igneous microstructures. Elements 3 (4), 239-245.

Joy, S., Saha, D., 1998. Influence of micaceous impurity on dynamically recrystallized quartz c-axis fabric in L-S tectonites from the Singhbhum Shear Zone and its footwall, Eastern India. J. Struct. Geol. 20 (11), 1509-1520.

Karato, S., 2008. Deformation of Earth materials: an introduction to the rheology of solid Earth. Cambridge University Press, 463 p.

Keller, L.M., Schmid, S.M., 2001. On the kinematics of shearing near the top of the Monte Rosa nappe and the nature of the Furgg zone in Val Loranco (Antrona valley, N. Italy): tectonometamorphic and paleogeographical consequences. Schweiz. Mineral. Petrogr. Mitt 81 (3), 347-367.

Keller, L., Hess, M., Fügenschuh, B., Schmid, S.M., 2005. Structural and metamorphic evolution of the Camughera - Moncucco, Antrona and Monte Rosa units southwest of the Simplon line, Western Alps. Eclogae Geol. Helvetiae 98 (1), 19-49.

Ketcham, R.A., 2005a. Computational methods for quantitative analysis of threedimensional features in geological specimens. Geosphere 1 (1), 32-41.

Ketcham, R.A., 2005b. Three-dimensional grain fabric measurements using highresolution X-ray computed tomography. J. Struct. Geol. 27 (7), 1217-1228.

Lacassin, R., 1987. Kinematics of ductile shearing from outcrop to crustal scale in the Monte Rosa nappe, Western Alps. Tectonics 6 (1), 69-88.

Law, R.D., 1990. Crystallographic fabrics: a selective review of their applications to research in structural geology. In: Knipe, R.J., Rutter, E.H. (Eds.), Deformation Mechanisms, Rheology and Tectonics, vol. 54, pp. 335-352.

Le Bayon, B., Pitra, P., Ballevre, M., Bohn, M., 2006a. Reconstructing P-T paths during continental collision using multi-stage garnet (Gran Paradiso nappe, Western Alps). J. Metamorph. Geol. 24 (6), 477-496.

Le Bayon, R., de Capitani, C., Frey, M., 2006b. Modelling phase-assemblage diagrams for magnesian metapelites in the system $\mathrm{K}_{2} \mathrm{O}-\mathrm{FeO}-\mathrm{MgO}-\mathrm{Al}_{2} \mathrm{O}_{3}-\mathrm{SiO}_{2}-$ $\mathrm{H}_{2} \mathrm{O}$ : geodynamic consequences for the Monte Rosa nappe, Western Alps. Contributions Mineral. Petrol. 151 (4), 395-412.

Lister, G.S., Hobbs, B.E., 1980. The simulation of fabric development during plastic deformation and its application to quartzite. J. Struct. Geol. 2, 355-370.

Liu, Y., Wang, F., Xu, J., Liang, Z., 1993. Estimation of the true orientation distribution function determination of the maximum-entropy method by the Taylor model. J. Applied Crystallogr. 26 (2), 268-271.

Lloyd, G.E., Butler, R.W.H., Casey, M., Tatham, D.J., Mainprice, D., 2011. Constraints on the seismic properties of the middle and lower continental crust. In: Prior, D.J. Rutter, E.H., Tatham, D.J. (Eds.), Deformation Mechanisms, Rheology and Tectonics: Microstructures, Mechanics and Anisotropy, Geological Society, London Special Publications, vol. 360, pp. 7-32. 
Lutterotti, L., Matthies, S., Wenk, H.R., 1999. MAUD (Material Analysis Using Diffraction): a User Friendly Java program for Rietveld Texture Analysis and More, vol. 2, p. 1599. Proceedings of the Twelfth International Conference on Textures of Materials (ICOTOM-12).

Mainprice, D., 1990. A FORTRAN program to calculate seismic anisotropy from the lattice preferred orientation of minerals. Comput. Geosci. 16 (3), 385-393.

Mainprice, D., Hielscher, R., Schaeben, H., 2011. Calculating anisotropic physical properties from texture data using the MTEX open-source package. In: Prior, D.J., Rutter, E.H., Tatham, D.J. (Eds.), Deformation Mechanisms, Rheology and Tectonics: Microstructures, Mechanics and Anisotropy, Geological Society, London Special Publications, vol. 360, pp. 175-192.

Mainprice, D., Humbert, M., 1994. Methods of calculating petrophysical properties from lattice preferred orientation data. Surv. Geophys. 15 (5), 575-592.

Matthies, S., Wagener, F., 1996. On a $1 / \mathrm{n}$ law in texture related single orientation analysis. Phys. Stat. Sol. B 196, K11-K15.

Matthies, S., Lutterotti, L., Wenk, H.R., 1997. Advances in texture analysis from diffraction spectra. J. Appl. Crystallogr. 30, 31-42.

Nicolas, A., 1987. Principles of Rock Deformation. Reidel, Dordrecht, p. 208.

Nicolas, A., Poirier, J.P., 1976. Crystalline Plasticity and Solid State Flow in Metamorphic Rocks. Wiley Interscience, New York, p. 444

Otani, M., Wallis, S., 2006. Quartz lattice preferred orientation patterns and static recrystallization: natural examples from the Ryoke belt, Japan. Geology 34 (7), 561.

Passchier, C.W., 1998. Monoclinic model shear zones. J. Struct. Geol. 20 (8), 11211137.

Passchier, C.W., Trouw, R.A.J., 2005. Microtectonics. Springer, 382 p.

Pleuger, J., Froitzheim, N., Derks, J.F., Kurz, W., Albus, J., Walter, J.M., Jansen, E., 2009. The contribution of neutron texture goniometry to the study of complex tectonics in the alps, neutron applications in Earth. Energy Environ. Sci., 283-317. Springer.

Ramsay, J.G., Huber, M.I., 1983. The Techniques of Modern Structural Geology. In: Strain Analysis, vol. 1. Academic Press, London, 307 pp.

Reinhardt, B., 1966. Geologie und Petrographie der Monte Rosa-Zone, der SesiaZone und des Canavese im Gebiet zwischen Valle d'Ossola und Valle Loana (Prov. Di Novara, Italien). Schweiz. Min. Petr. Mitt 46, 553-678.

Rietveld, H.M., 1969. A profile refinement method for nuclear and magnetic structures. J. Appl. Crystallogr. 2 (2), 65-71.

Sahagian, D.L., Proussevitch, A.A., 1998. 3D particle size distributions from 2D observations: stereology for natural applications. J. Volcanol. Geotherm. Res. 84 (3), 173-196

Schmid, S.M., Casey, M., 1986. Complete fabric analysis of some commonly observed quartz c-axis patterns. Geophys. Monogr. Ser. 36, 263-286.

Shea, T., Houghton, B.F., Gurioli, L., Cashman, K.V., Hammer, J.E., Hobden, B.J., 2010. Textural studies of vesicles in volcanic rocks: an integrated methodology. J. Volcanol. Geoth. Res. 190, 271-289.

Siegesmund, S., Kern, H., Vollbrecht, A., 1991. The effect of oriented microcracks on seismic velocities in an ultramylonite. Tectonophysics 186 (3), 241-251.

Spalla, M.I., Zucali, M., 2004. Deformation vs. metamorphic re-equilibration heterogeneities in polymetamorphic rocks: a key to infer quality PTdt path. Period. Mineral. 73, 249-257.

Stipp, M., Stünitz, H., Heilbronner, R., Schmid, S.M., 2002. The eastern Tonale fault zone: a natural laboratory for crystal plastic deformation of quartz over a temperature range from 250 to $700^{\circ}$ C. J. Struct. Geol. 24 (12), 1861-1884.

Sullivan, W.A., 2013. L tectonites. J. Struct. Geol. 50, 161-175. http://dx.doi.org/10. 1016/j.jsg.2012.01.022.

Sullivan, W.A., Beane, R.J., 2010. Asymmetrical quartz crystallographic fabrics produced during constrictional deformation. J. Struct. Geol. 32, 1430-1443.

Tafforeau, P., Boistel, R., Boller, E., Bravin, A., Brunet, M., Chaimanee, Y., Cloetens, P., Feist, M., Hoszowka, J., Jaeger, J.J., Kay, R.F., Lazzari, V., Marivaux, L., Nel, A., Nemoz, C.. Thibault, X., Vignaud, P., Zabler, S., 2006. Applications of X-ray synchrotron microtomography for non-destructive 3D studies of paleontological specimens. Appl. Phys. A 83, 195-202.

Tartarotti, P., Zucali, M., Panseri, M., Lissandrelli, S., Capelli, S., Ouladdiaf, B., 2011. Mantle origin of the Antrona serpentinites (Antrona ophiolite, Pennine Alps) as inferred from microstructural, microchemical, and neutron diffraction quantitative texture analysis. Ofioliti 36, 167-189.

Tatham, D.J., Lloyd, G.E., Butler, R.W.H., Casey, M., 2008. Amphibole and lower crustal seismic properties. Earth Planet. Sci. Lett. 267 (1), 118-128. ten Grotenhuis, S.M., Passchier, C.W., Bons, P.D., 2002. The influence of strain localisation on the rotation behaviour of rigid objects in experimental shear zones. J. Struct. Geol. 24 (3), 485-499.

Tromba, G., Longo, R., Abrami, A., Arfelli, F., Astolfo, A., Bregant, P., Brun, F., Casarin, K., Chenda, V., Dreossi, D., Hola, M., Kaiser, J., Mancini, L., Menk, R.H., Quai, E., Quaia, E., Rigon, L., Rokvic, T., Sodini, N., Sanabor, D., Schultke, E., Tonutti, M., Vascotto, A., Zanconati, F., Cova, M., Castelli, E., 2010. The SYRMEP beamline of elettra: clinical mammography and bio-medical applications. AIP Conf. Proc. 1266 (1), 18-23.

Turner, F.J., Weiss, L.E., 1963. Structural analysis of Metamorphic Tectonites. MacGraw-Hill, New York, p. 545.

Unzog. W., Kurz, W., 2000. Progressive development of lattice preferred orientations (LPOs) of naturally deformed quartz within a transpressional collision zone (Panafrican Orogen in the Eastern Desert of Egypt). J. Struct. Geol. 22 (11), 1827-1835.

Vaughan, M.T., Guggenheim, S., 1986. Elasticity of muscovite and its relationship to crystal structure. J. Geophys. Res. 91 (B5), 4657-4664.

Voltolini, M., Marinoni, N., Mancini, L., 2011a. Synchrotron X-ray computed microtomography investigation of a mortar affected by alkali-silica reaction: a quantitative characterization of its microstructural features. J. Materials Sci., 19.

Voltolini, M., Zandomeneghi, D., Mancini, L., Polacci, M., 2011b. Texture analysis of volcanic rock samples: quantitative study of crystals and vesicles shape preferred orientation from X-ray microtomography data. J. Volcanol. Geotherm. Res. 202 (1-2), 83-95.

Voltolini, M., Wenk, H.-R., Mondol, N.H., Bjørlykke, K., Jahren, J., 2008. Anisotropy of experimentally compressed kaolinite-illite-quartz mixtures. Geophysics 74 (1), D13-D23.

Wendt, A.S., Bayuk, I.O., Covey-Crump, S.J., Wirth, R., Lloyd, G.E., 2003. An experimental and numerical study of the microstructural parameters contributing to the seismic anisotropy of rocks. J. Geophys. Res, 108 (B8), 2365.

Wenk, H.R., 2006. Neutron diffraction texture analysis. In: Neutron Scattering in Earth Sciences, Reviews in Mineralogy and Geochemistry, 63. Mineralogical Society of America, pp. 399-426.

Wenk, H.R., Matthies, S., Donovan, J., Chateigner, D., 1998. Beartex: a windowsbased program system for quantitative texture analysis. J. Appl. Crystallogr. 31, 262-269.

Wenk, H.R., Kanitpanyacharoen, W., Voltolini, M., 2010. Preferred orientation of phyllosilicates: comparison of fault gouge, shale and schist. J. Struct. Geol. 32 (4), 478-489.

Wenk, H.R., Cont, L., Xie, Y., Lutterotti, L., Ratschbacher, L., Richardson, J., 2001. Rietveld texture analysis of Dabie Shan eclogite from TOF neutron diffraction spectra. J. Appl. Crystallogr. 34 (4), 442-453.

Woodcock, N.H., Naylor, M.A., 1983. Randomness testing in three-dimensional orientation data. J. Struct. Geol. 5 (5), 539-548.

Young, R.A., 1993. The Rietveld Method, International Union of Crystallography Monographs on Crystallography 5. IUCr/Oxford University Press, Oxford, p. 312.

Zandomeneghi, D., Voltolini, M., Mancini, L., Brun, F., Dreossi, D., Polacci, M., 2010. Quantitative analysis of X-ray microtomography images of geomaterials. Appl. Volcanic Rocks: Geosph. 6 (6), 793-804.

Zucali, M., Chateigner, D., Dugnani, M., Lutterotti, L., Ouladdiaf, B., 2002. Quantitative texture analysis of glaucophanite deformed under eclogite facies conditions (Sesia-Lanzo Zone, Western Alps); comparison between X-ray and neutron diffraction analysis. Geol. Soc. Spec. Publ. 200, 239-253.

Zucali, M., Barberini, Chateigner, D., Ouladdiaf, B., Lutterotti, L., 2010. Brittle plus plastic deformation of gypsum aggregates experimentally deformed in torsion to high strains: quantitative microstructural and texture analysis from optical and diffraction data. In: Spalla, M.I., Marotta, A.M., Gosso, G. (Eds.), Advances in Interpretation of Geological Processes: Refinement of Multi-scale Data and Integration in Numerical Modelling, 332. Geological Society, London, pp. 7998. http://dx.doi.org/10.1144/SP332.60305-8719/10. Special Publications.

Zucali, M., Tartarotti, P., Capelli, S., Ouladdiaf, B., 2012. Multiscalar structural study of the ultramafic rocks of the Antrona ophiolite (Pennine Alps). J. Virtual Explor. 41 paper 4. 10.3809/jvirtex.2011.00295.

Zucali, M., Fontana, E., Panseri, M., Tartarotti, P., Capelli, S., Ouladdiaf, B., 2014. Submarine lava flow direction revealed by neutron diffraction analysis in mineral lattice orientation. Geochem. Geophys. Geosyst. 15. http://dx.doi.org/ 10.1002/2013GC005044. 